\title{
Characteristics of Ice Cloud-Precipitation of Warm Season Mesoscale Convective Systems over the Great Plains
}

\author{
JiNGJING TIAN, ${ }^{\mathrm{a}}$ XIQUAN DONG, AND BAIKE XI \\ Department of Hydrology and Atmospheric Sciences, The University of Arizona, Tucson, Arizona \\ ZHE FENG \\ Atmospheric Sciences and Global Change Division, Pacific Northwest National Laboratory, Richland, Washington
}

(Manuscript received 9 August 2019, in final form 16 December 2019)

\begin{abstract}
In this study, the mesoscale convective systems (MCSs) are tracked using high-resolution radar and satellite observations over the U.S. Great Plains during April-August from 2010 to 2012. The spatiotemporal variability of MCS precipitation is then characterized using the Stage IV product. We found that the spatial variability and nocturnal peaks of MCS precipitation are primarily driven by the MCS occurrence rather than the precipitation intensity. The tracked MCSs are further classified into convective core (CC), stratiform rain (SR), and anvil clouds regions. The spatial variability and diurnal cycle of precipitation in the SR regions of MCSs are not as significant as those of MCS precipitation. In the SR regions, the high-resolution, long-term ice cloud microphysical properties [ice water content (IWC) and ice water paths (IWPs)] are provided. The IWCs generally decrease with height. Spatially, the IWC, IWP, and precipitation are all higher over the southern Great Plains than over the northern Great Plains. Seasonally, those ice and precipitation properties are all higher in summer than in spring. Comparing the peak timings of MCS precipitation and IWPs from the diurnal cycles and their composite evolutions, it is found that when using the peak timing of IWP $\mathrm{SR}_{\mathrm{SR}}$ a reference, the heaviest precipitation in the MCS convective core occurs earlier, while the strongest SR precipitation occurs later. The shift of peak timings could be explained by the stratiform precipitation formation process. The IWP and precipitation relationships are different at MCS genesis, mature, and decay stages. The relationships and the transition processes from ice particles to precipitation also depend on the low-level humidity.
\end{abstract}

\section{Introduction}

Clouds and precipitation are key components in the hydrological and energy cycles of the climate system (Hartmann et al. 1992; Stephens et al. 2012). Understanding the transition process from cloud to precipitation is a highly desired goal (e.g., Kubar et al. 2009; Khain et al. 2013; Lebsock et al. 2013; Tian et al. 2019). Quantitative links between cloud microphysical properties and precipitation are found for low-level warm clouds, especially for marine stratocumulus clouds (e.g., Wood 2012; Wu et al. 2015, 2017, 2018). The cloud base rain rate $\left(\mathrm{RR}_{\mathrm{cb}}\right)$ is shown to increase with

\footnotetext{
${ }^{\text {a }}$ Current affiliation: Lawrence Livermore National Laboratory, Livermore, California.
}

Corresponding author: Dr. Xiquan Dong, xdong@email.arizona.edu liquid water path (LWP), where $\mathrm{RR}_{\mathrm{cb}}$ is proportional to $L_{W P}^{1.75}$ (Comstock et al. 2004). Over the majority of land areas, the correlation between ice water path (IWP) and surface rain rate is $\sim 0.4$, which is found from the precipitation radar and microwave radiometer observations from the Tropical Rainfall Measuring Mission (TRMM) satellites (You and Liu 2012). However, none of these studies investigated the links between cloud properties and rain intensity for deep convective systems.

The largest form of deep convective storms is known as a mesoscale convective system (MCS), which is an ensemble of cumulonimbus clouds that are organized into a storm complex and produce distinct mesoscale circulations (Houze 2004). In the central United States, MCSs contribute between $30 \%$ and $70 \%$ of warmseason rainfall (Feng et al. 2016; Nesbitt et al. 2006), and they are often associated with severe weather 
phenomena, such as tornadoes, flash flooding, derechos, and hail (Houze 2004; Bentley and Sparks 2003). MCSs also connect the mesoscale and large-scale circulations through the vertical transport of momentum, water, and mass from the lower atmospheric levels to the free troposphere (Fiolleau and Roca 2013).

Accurately simulating MCSs has been challenging even using cloud-resolving models (CRMs), which can benefit from finer grid resolution and more sophisticated physical parameterizations than global circulation models (GCMs) (Fan et al. 2017; Han et al. 2019). Although CRMs can qualitatively simulate some cloud properties in the stratiform region of MCSs, underestimation of the stratiform precipitation has been a long-standing model issue, and the reasons for the underestimation are still not well understood (e.g., Varble et al. 2014; Morrison et al. 2015; Fridlind et al. 2017). The reasons for the differences between observations and model simulations are very complicated and could be caused by the problems in the initial conditions, dynamics and thermodynamics, aerosol and cloud microphysics parameterizations, and complex interactions and feedbacks between any of these factors. However, better understanding of the ice cloud properties in the precipitating system would help reduce biases in simulated stratiform precipitation (e.g., Han et al. 2019). An accurate estimation of the spatiotemporal distribution of the ice properties is key parameters for evaluating and improving numerical weather prediction (Stephens et al. 2002).

Ice particles comprise a large portion of the MCS's cloud mass, and ice melting is a dominant rainfall formation process in the stratiform precipitation associated with MCSs (Bringi and Chandrasekar 2001). The stratiform region of MCSs is formed when ice particles generated from convective cores are advected by the outflow and then the depositional growth begins (Herzegh and Hobbs 1980). When the ice particles were growing and falling into low dry layers, the ice particles that survived longer distances are larger and eventually enhance the precipitation rate (Heymsfield 1977). Using radar and in situ aircraft measurements, studies have found that, with faster updraft velocities in the convective core regions, IWC values and precipitation rates are both considerably higher in stratiform ice clouds (Heymsfield 1977; Carbone and Bohne 1975). Based on these findings, the precipitation rate is estimated based on retrieved IWC and/or IWP in some satellite remote sensing studies (Ferraro et al. 2000; Zhao and Weng 2002; Weng et al. 2003). Thus, further investigation of the links between ice cloud properties and precipitation for MCSs has a great potential to improve model simulations and satellite precipitation estimations.

The characteristics of MCS precipitation have been studied relatively extensively over the continental United States (e.g., Nesbitt et al. 2006; Prein et al. 2017; Feng et al. 2018). However, few studies investigated the ice cloud properties of MCSs over a large domain using long-term ground-based observations and retrievals, and at the same time, few studies investigated the link between ice properties and precipitation in the MCSs. The geographical focus of this study is the Great Plains $\left(32^{\circ}-48^{\circ} \mathrm{N}, 95^{\circ}-103^{\circ} \mathrm{W}\right)$, where the majority of its annual precipitation occurs during the warm season, with up to $60 \%$ of total precipitation connected to MCSs (Ashley et al. 2003). This study is the first study to provide a high-resolution, long-term analysis of the ice cloud properties (IWCs and IWPs) for MCSs over the Great Plains. The vertical and spatiotemporal distributions of MCS IWCs and IWPs retrieved from ground-based radar observations are investigated, and more importantly, the relationships between MCS IWP and surface precipitation rate are analyzed in this study. A brief description of the datasets used in this study is given in section 2. The spatiotemporal characteristics of MCS precipitation and ice cloud properties during warm seasons over the Great Plains are investigated in sections 3 and 4. The relationships between IWP and precipitation rate are discussed in section 5. Major findings from this study are summarized in section 6 .

\section{Dataset}

\section{a. Observational datasets}

To obtain various characteristics of MCSs in the Great Plains, in this study, three long-term high-resolution observational datasets are used, which are geostationary satellite infrared brightness temperature, ground-based radar reflectivity, and Stage IV multisensor precipitation rate. The brightness temperature $T_{b}$ data (Janowiak et al. 2001) are produced by the National Oceanic and Atmospheric Administration (NOAA) Climate Prediction Center and archived at NASA Goddard Earth Sciences Data and Information Services Center. The ground-based radar measurements are the mosaic National Weather Service Next-Generation Radar (NEXRAD) radar reflectivity from the GridRad dataset (Bowman and Homeyer 2017). The hourly GridRad radar reflectivity data covering the CONUS has $0.02^{\circ} \times 0.02^{\circ}$ spatial and $1-\mathrm{km}$ vertical resolutions. Ground clutter and other nonmeteorological echoes in the radar data are removed follow set of quality 
control procedures provided by GridRad (http:// gridrad.org/software.html). Precipitation associated with MCSs is obtained using the hourly Stage IV multisensor precipitation dataset produced by the 12 River Forecast Centers in the continental United States from the National Centers for Environment Prediction (Lin 2011). The Stage IV product has been used as a reference precipitation dataset in many satellite and model verification studies (AghaKouchak et al. 2011; Mehran and AghaKouchak 2014; Smalley et al. 2014). Atmospheric large-scale environments associated with MCSs are obtained from the North American Regional Reanalysis (NARR) reanalysis dataset, which was developed to improve upon the NCAR-NCEP global reanalysis by more accurately capturing the regional hydrological cycle, diurnal cycle, and other important features. The horizontal and vertical resolutions are $32 \mathrm{~km}$ and $50 \mathrm{hPa}$, and temporal resolution is $3 \mathrm{~h}$.

\section{b. MCSs identification and tracking}

We used the 13-yr high-resolution MCSs database (https://doi.org/10.5439/1571643) developed by Feng et al. (2019) in this study. MCSs were identified and tracked using the Flexible Object Tracker (FLEXTRKR) algorithm (Feng et al. 2018). The method makes use of satellite brightness temperature $T_{b}$ data to track large cold cloud systems (CCSs; $T_{b}<241 \mathrm{~K}$ ) associated with deep convective clouds, and subsequently uses the $3 \mathrm{D}$ radar reflectivity data to identify large precipitation features (PFs) that contain intense convection. Note that the PFs were defined as the contiguous radar echoes at $2-\mathrm{km}$ height greater than $17 \mathrm{~dB} Z$. To create a synthesized dataset for MCSs identification and tracking, the GridRad and Stage IV data were regridded onto the satellite 4-km grid (Feng et al. 2019).

The MCSs we focus on in this study are the long-lived and intense MCSs (Feng et al. 2018, 2019). An MCS is defined as a large CCS with area $>6 \times 10^{4} \mathrm{~km}^{2}$, containing a PF major axis length $>100 \mathrm{~km}$, a convective feature with radar reflectivity $>45 \mathrm{dBZ}$ at any vertical level, and all three criteria are met continuously for at least $6 \mathrm{~h}$. Note that the MCS starting (convective initiation) time is defined as the first hour when a CCS is detected.

For a tracked MCS, three life cycle stages objectively identified based on the definition in Feng et al. (2018) are also used in this study: 1 ) MCS genesis, which is the first hour when the major axis length of convective feature exceeds $100 \mathrm{~km}$; 2) MCS mature is defined as the period when the convective feature maintains its major axis length of $100 \mathrm{~km}$ and the stratiform rain area exceeds its mean value averaged over the entire duration of the MCS; 3) the MCS decay stage is the period when the convective feature's major axis length is less than $100 \mathrm{~km}$ or the stratiform rain area decreases to below the mean value of the MCS.

In addition to its life cycle, a tracked MCS is classified into three components, convective core (CC), stratiform rain (SR), and anvil clouds (AC) (Feng et al. 2011). The SR regions have the largest coverage of warm-season rainfall over the midlatitudes, while the $\mathrm{CC}$ regions account for the most intense precipitation. Some classification methods primarily use the horizontal texture of radar reflectivity to differentiate convective echoes that have higher peakedness in echo intensity compared to the surrounding background (Feng et al. 2011; Starzec et al. 2017). The temporal resolution of the GridRad radar dataset is $1 \mathrm{~h}$, which provides a "snapshot" of radar reflectivity. It is possible that the classification conducted using one radar snapshot in an hour may not be reliably used to separate convective/stratiform precipitation from the hourly accumulated precipitation dataset. This is mainly because of the propagating nature of the MCS convective cores. The actual convective precipitation region is likely larger than that represented by the hourly radar snapshot. Thus, in this study, we simply adopt previous studies (e.g., Han and Hong 2018; Giangrande et al. 2014) to use the Stage IV precipitation rate to classify the convective and stratiform echoes. A threshold of $10 \mathrm{~mm} \mathrm{~h}^{-1}$ is used to separate convective and stratiform regions of MCSs. The area of precipitation rate less than $0.2 \mathrm{~mm} \mathrm{~h}^{-1}$ is regarded as the MCS AC region.

Figure 1 shows the probability density functions (PDFs) and cumulative distribution functions (CDFs) of MCS lifetime and area that occurred during the warm seasons (April-August) from 2010 to 2012 over the Great Plains $\left(32^{\circ}-48^{\circ} \mathrm{N}, 95^{\circ}-103^{\circ} \mathrm{W}\right)$. There is a total of 453 MCSs selected during the 3 -yr period over the Great Plains in this study with a mean duration of $18.23 \mathrm{~h}$ and mean area of $172.62 \times 10^{3} \mathrm{~km}^{2}$.

\section{c. Estimations of MCS ice properties}

The GridRad Radar reflectivities are used to retrieve IWC profiles in midlatitude MCSs (Tian et al. 2016). NEXRAD IWPs are obtained by vertically integrating radar reflectivity-based IWC profiles in the ice-phasedominated layers from $5 \mathrm{~km}$ to NEXRAD radar echo top (Tian et al. 2018). The maximum reliable IWP value used in this study is $10 \mathrm{~kg} \mathrm{~m}^{-2}$ (larger values represent less than $1 \%$ of the samples). The IWC retrieval algorithm was evaluated by the aircraft in situ measurements during the Midlatitude Continental Convective Clouds Experiment (MC3E) field campaign and the Bow Echo and Mesoscale Convective Vortex Experiment 

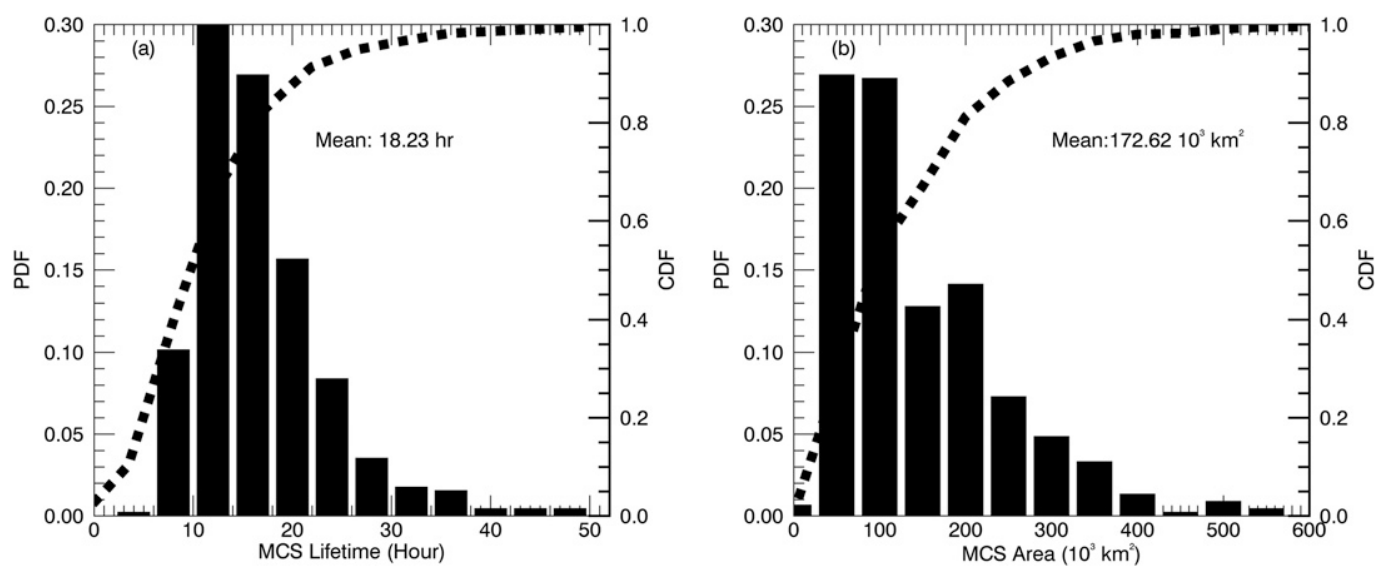

FIG. 1. Probability density functions (PDFs) and cumulative distribution functions (CDFs) of MCS (a) lifetime and (b) area during the warm seasons (April-August) from 2010 to 2012 over the Great Plains $\left(32^{\circ}-48^{\circ} \mathrm{N}\right.$, $\left.95^{\circ}-103^{\circ} \mathrm{W}\right)$. Numbers in the legends are the averaged duration (h) in (a) and area $\left(10^{3} \mathrm{~km}^{2}\right)$ in (b).

(BAMEX) (Tian et al. 2016). MC3E was conducted in 2011 from April to June over the southern Great Plains, and BAMEX was conducted in 2003 from May to July over the Great Plains. The retrieved IWC uncertainty for the stratiform rain and thick anvil regions of MCSs is around $20 \%-40 \%$ validated against the in situ measurements during MC3E and BAMEX. The NEXRAD $Z_{e}$-retrieved IWCs and IWPs in Tian et al. (2016) are also compared with the ones derived from the polarimetric observations developed by $\mathrm{Lu}$ et al. (2015), which used the specific differential phase $K_{\mathrm{dp}}$ to retrieve IWC values. Cui et al. (2019) compared the two types of retrievals and found that the $Z_{e}$-retrieved IWP from Tian et al. (2016), on average, is $13 \%$ larger than that from $K_{\mathrm{dp}}$-based retrieval in Lu et al. (2015).

\section{MCS precipitation variability}

An MCS consists of three different regions: a CC region with heavy precipitation, an SR region with moderate precipitation and an $\mathrm{AC}$ region with almost no precipitation. MCS precipitation considering all three MCS regions (CC, SR, and $\mathrm{AC}$ ) was discussed in previous studies (e.g., Jiang et al. 2006; Feng et al. 2019). In this study, in addition to calculating the mean precipitation rates in all three regions of MCSs, we also calculate the mean precipitation of MCSs for precipitation regions (in CC and SR regions) only. $\mathrm{PR}_{\mathrm{all}}$ and $\mathrm{PR}_{\mathrm{CC}+\mathrm{SR}}$ are used to represent the two types of MCS precipitation throughout this study. It is noted that, the mean $\mathrm{PR}_{\mathrm{all}}$ and $\mathrm{PR}_{\mathrm{CC}+\mathrm{SR}}$ are calculated by dividing the total MCS precipitation amount (in $\mathrm{mm}$ ) by the MCS occurrences (in hours), rather than by the total time period. The geographical and seasonal variations of MCS precipitation are shown in Figs. 2c-f.
The $\mathrm{PR}_{\text {all }}$ values in Figs. $2 \mathrm{c}$ and $2 \mathrm{~d}$ are on the order of several millimeters per day and much smaller than the $\mathrm{PR}_{\mathrm{CC}+\mathrm{SR}}$ in Figs. 2e and 2f, which is because the areal coverage of the AC regions is about an order of magnitude larger and 3 times larger than those of precipitating CC and SR regions in the MCSs (Feng et al. 2011). The mean value of $P_{\mathrm{all}}$ over the NGP and $S G P$ is $\sim 1 \mathrm{~mm}$ day $^{-1}$, while the mean value for $\mathrm{PR}_{\mathrm{CC}+\mathrm{SR}}$ is $\sim 3-4 \mathrm{~mm} \mathrm{~h}^{-1}$ (Table 1 ).

From the spatial distributions of $\mathrm{PR}_{\mathrm{all}}$ in Figs. $2 \mathrm{c}$ and $2 \mathrm{~d}$, it is clearly seen that there is a gradual northward migration of MCSs from the southern Great Plains (SGP; $32^{\circ}-40^{\circ} \mathrm{N}, 95^{\circ}-103^{\circ} \mathrm{W}$ ) in spring (Fig. $2 \mathrm{c}$ ) to the northern Great Plains (NGP; $40^{\circ}-48^{\circ} \mathrm{N}, 95^{\circ}-103^{\circ} \mathrm{W}$ ) in summer (Fig. 2d). In spring, the $\mathrm{PR}_{\text {all }}$ is larger over the SGP $\left(1.39 \mathrm{~mm} \mathrm{day}^{-1}\right)$ than that over the NGP $\left(1.03 \mathrm{~mm} \mathrm{day}^{-1}\right)$, while in summer, the $\mathrm{PR}_{\mathrm{all}}$ is larger over the NGP $\left(1.21 \mathrm{~mm} \mathrm{day}^{-1}\right)$ than that over the SGP $\left(0.73 \mathrm{~mm} \mathrm{day}^{-1}\right)$. The difference between mean $\mathrm{PR}_{\text {all }}$ values is highly related to the MCS occurrence (data sample numbers). The spatial distribution of MCS precipitation $\left(\mathrm{PR}_{\text {all }}\right)$ exhibits a close resemblance to the MCS occurrence (Figs. 2a,b). The high occurrence (data sample numbers) of MCSs at the NGP in summer is related to the midtroposphere shortwave perturbations generated over the Rocky Mountains (Wang et al. 2011a,b). The midtroposphere shortwave perturbations would generate disturbances and collocate with sufficient low-level moisture and instability in summer, so that more MCSs can be generated over the NGP during summer months (Wang et al. 2011a,b). The MCSs distributions from the 3-yr dataset in this study are consistent with a 13-yr record reported by Feng et al. (2019), suggesting the 3-yr (2010-12) dataset is representative of the MCS climatology in this region. 
(a) Spring MCS Distribution

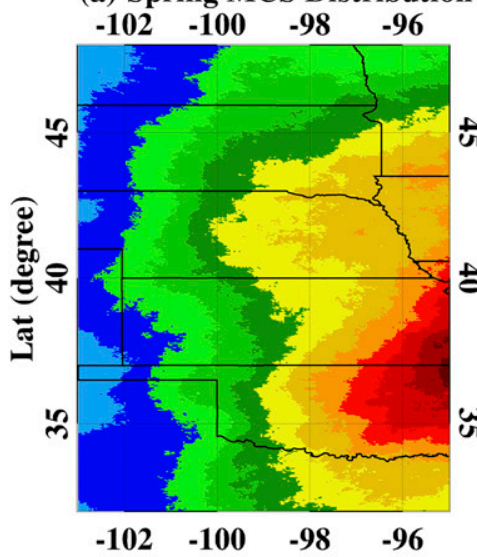

Lon (degree)

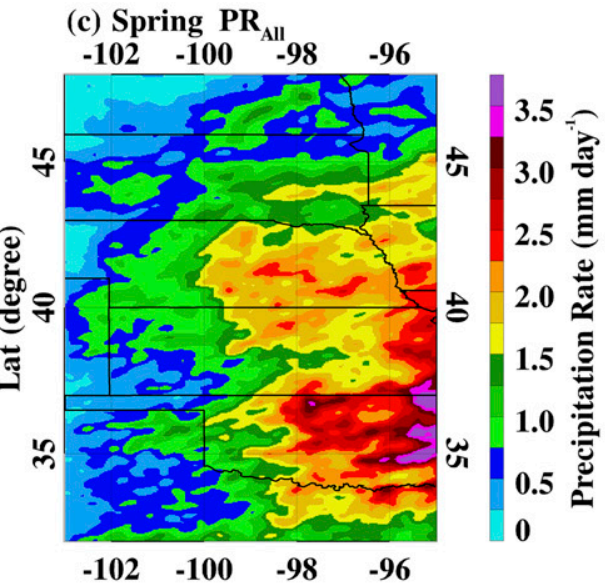

Lon (degree)

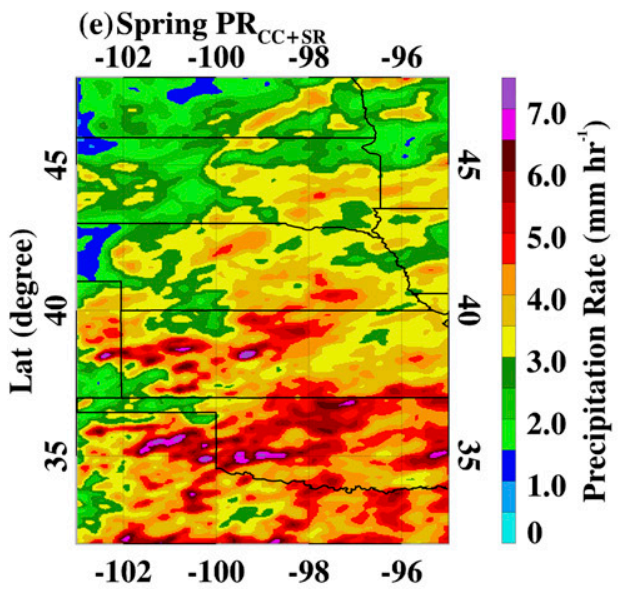

Lon (degree) (b) Summer MCS Distribution

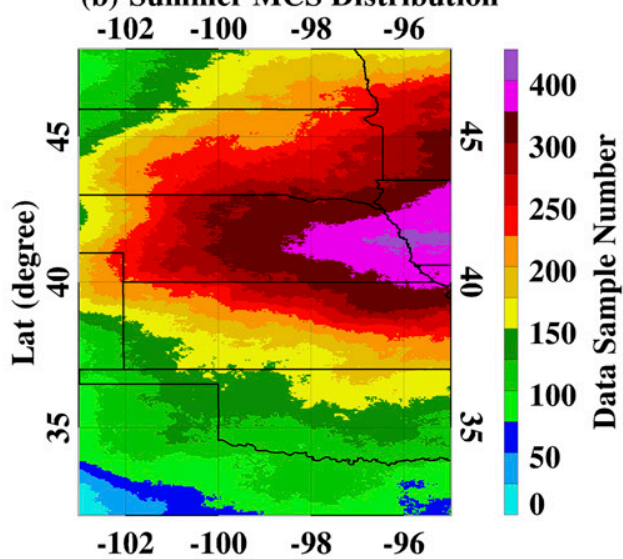

Lon (degree)

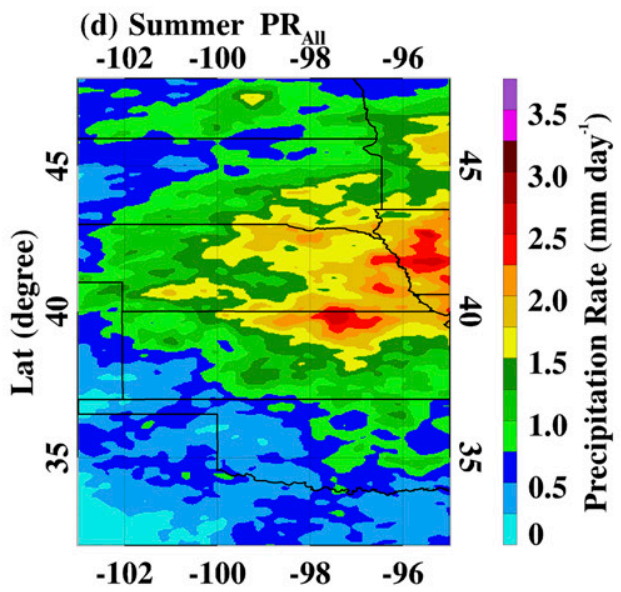

Lon (degree)

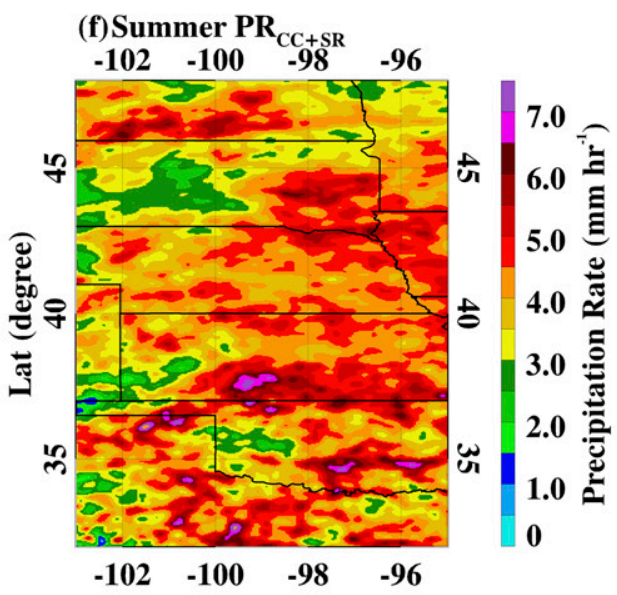

Lon (degree)

FIG. 2. Spatial distributions of the data sample numbers (each sample is an hour) of MCSs during two seasons in 2010-12: (a) April-May (spring) and (b) June-August (summer). (c),(d) The spatial distributions of MCS precipitation rates for all samples, including the samples in the convective core (CC), stratiform rain (SR), and anvil regions (AC) of MCSs. (e),(f) As in (c) and (d), but for the MCS precipitation that is the mean precipitation rate in the $\mathrm{CC}$ and SR regions of MCSs. 
TABLE 1. The means and standard deviations of MCS precipitation at the northern Great Plains $\left(\mathrm{NGP} ; 40^{\circ}-48^{\circ} \mathrm{N}, 95^{\circ}-103^{\circ} \mathrm{W}\right)$ and southern Great Plains (SGP; $32^{\circ}-40^{\circ} \mathrm{N}, 95^{\circ}-103^{\circ} \mathrm{W}$ ) in spring and summer. $\mathrm{PR}_{\text {all }}$ and $\mathrm{PR}_{\mathrm{CC}+\mathrm{SR}}$ represent the mean values of $\mathrm{MCS}$ precipitation with and without considering samples in the (little precipitating) anvil regions of MCSs.

\begin{tabular}{lcccr}
\hline \hline & NGP spring & NGP summer & SGP spring & SGP summer \\
\hline $\mathrm{PR}_{\mathrm{all}}\left(\mathrm{mm} \mathrm{day}^{-1}\right)$ & $1.03 \pm 0.60$ & $1.21 \pm 0.48$ & $1.39 \pm 0.80$ & $0.73 \pm 0.46$ \\
$\mathrm{PR}_{\mathrm{CC}+\mathrm{SR}}\left(\mathrm{mm} \mathrm{h}^{-1}\right)$ & $2.83 \pm 0.75$ & $4.03 \pm 0.76$ & $4.15 \pm 0.94$ & $4.27 \pm 0.94$ \\
\hline
\end{tabular}

The $\mathrm{PR}_{\mathrm{CC}+\mathrm{SR}}$ values are larger over the SGP than over the NGP in both spring and summer. On average, the mean precipitation over the Great Plains during summer $\left(4.18 \mathrm{~mm} \mathrm{~h}^{-1}\right)$ is $16 \%$ more than that in spring $\left(3.49 \mathrm{~mm} \mathrm{~h}^{-1}\right)$. The mean values of $\mathrm{PR}_{\mathrm{CC}+\mathrm{SR}}$ over the NGP and SGP in spring and summer are also listed in Table 1. The precipitation differences between spring and summer are related to different large-scale environments and thermodynamics (Feng et al. 2019; Song et al. 2019). During spring, MCSs often initiate ahead of the midlevel trough with low-level convergence and upper-level divergence, combining with a strong lowlevel jet bringing moisture. However, in summer, MCSs often initiate over or downwind of a high pressure ridge.
In addition, the warm surface and moist low-levels in summer result in the high instability and favorable thermodynamics to support MCS genesis.

Time-distance plots (often referred as Hovmöller diagrams) are commonly used for the diagnosis of coherent signals in climate science (e.g., Nakazawa 1988). Figure 3 shows the diurnal cycles of MCS occurrence as a function of latitude or longitude during spring and summer, respectively. It is seen that the peak occurrences of $\mathrm{PR}_{\text {all }}$ are around midnight in both spring and summer, except for the regions south of $34^{\circ} \mathrm{N}$ (Figs. 3a,b). Correspondingly, the peaks of MCS precipitation $\left(\mathrm{PR}_{\mathrm{all}}\right)$ occur around local midnight over most of the Great Plains in both spring and (a) Spring MCS Distribution

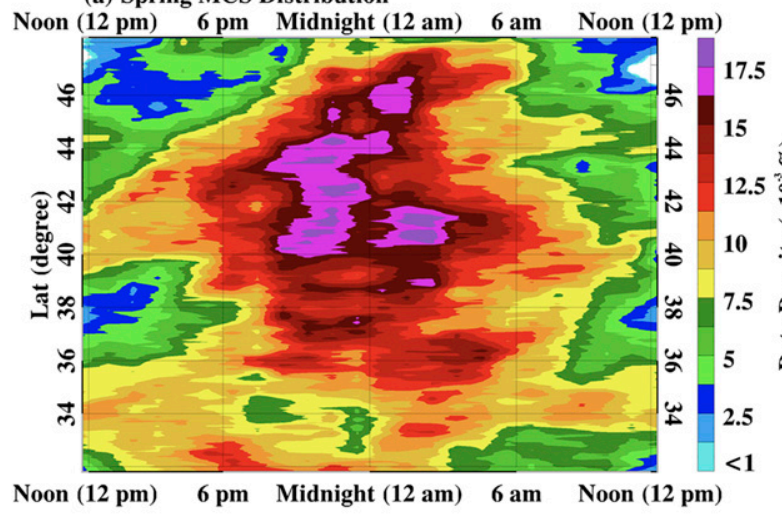

Local Time

(c) Spring MCS Distribution

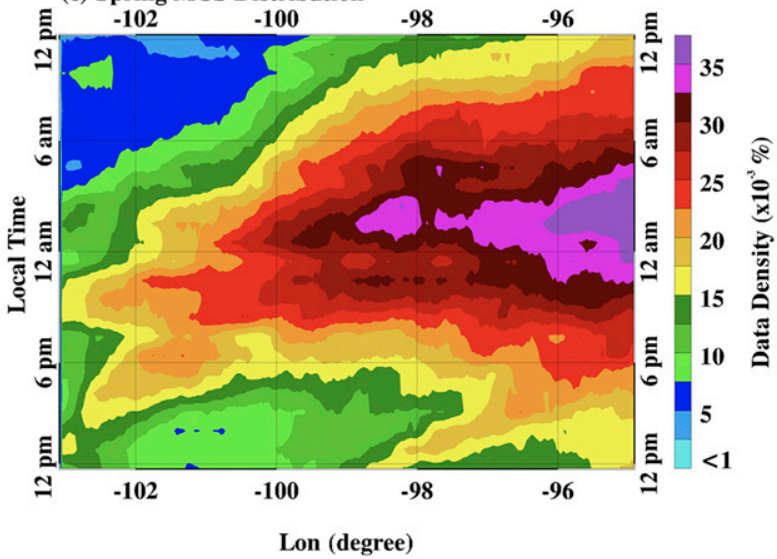

(b) Summer MCS Distribution

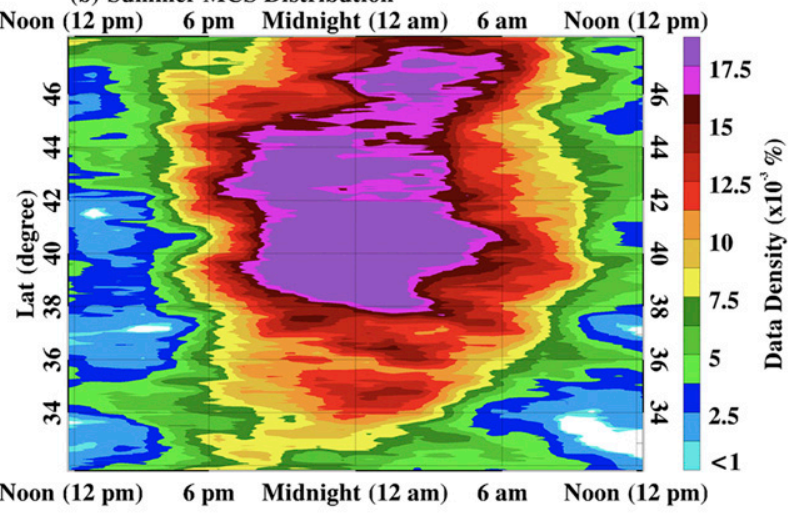

Local Time

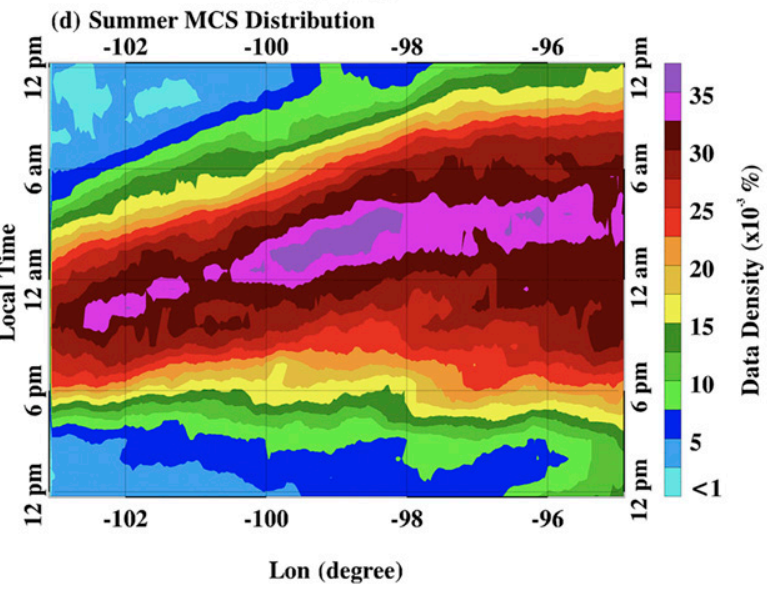

FIG. 3. Data densities of the diurnal cycles of MCS distributions as a function of latitude and longitude during spring and summer. 

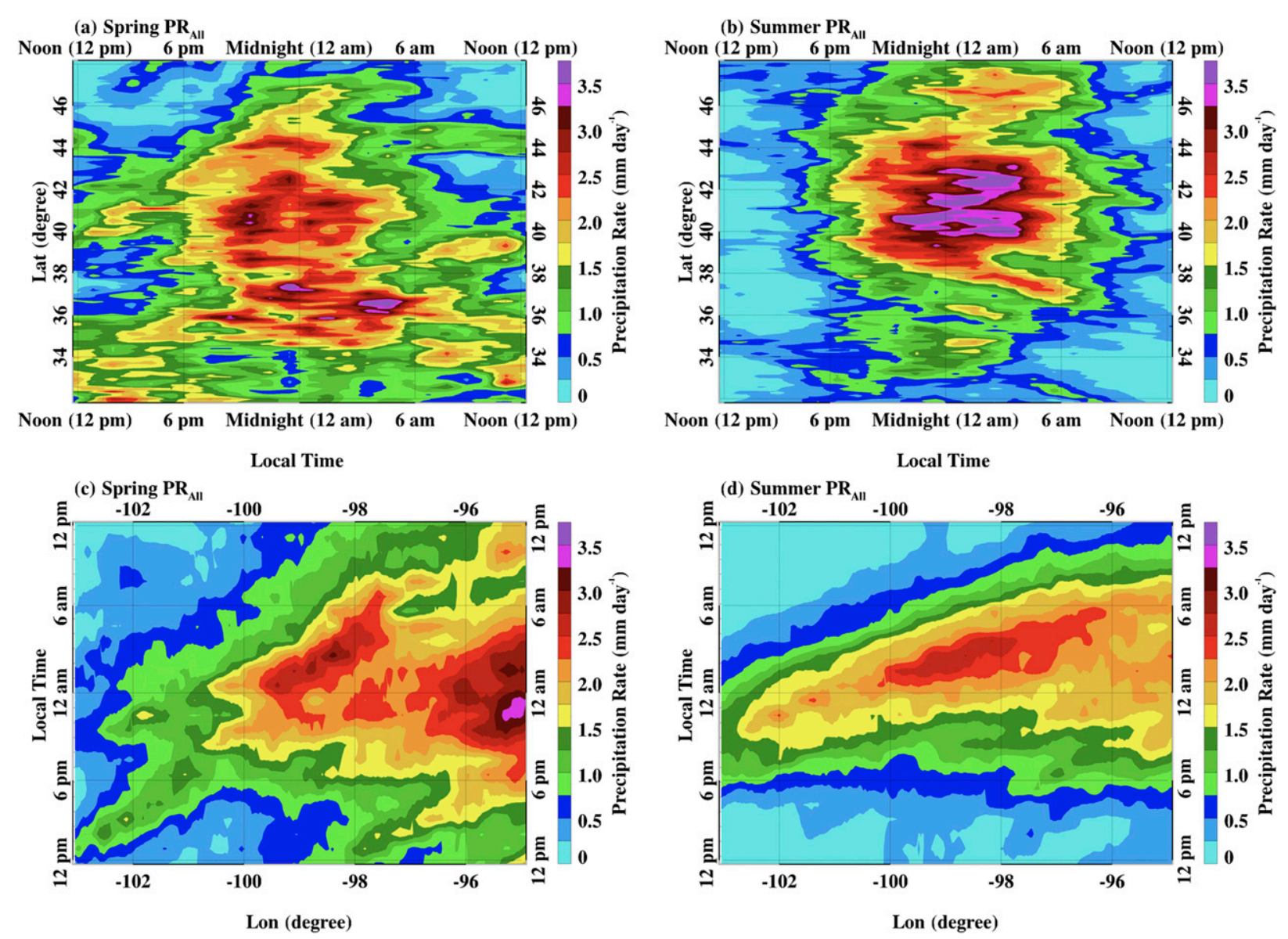

FIG. 4. Diurnal cycles of the precipitation rates $\left(\mathrm{PR}_{\text {all }}\right)$ for all MCS samples shown in Fig. 3 as a function of latitude and longitude during spring and summer.

summer (Figs. 4a,b) because $\mathrm{PR}_{\mathrm{all}}$ strongly correlates with MCS occurrence. The characteristic of a nocturnal precipitation peak is consistent with the findings from many previous studies. They also found that MCSs have nocturnal peak precipitation in the Great Plains during the warm seasons (e.g., Carbone et al. 2002; Jiang et al. 2006; Feng et al. 2019; Wang et al. 2019).

The diurnal cycles of precipitation rates in the SR and $\mathrm{CC}$ regions of MCSs $\left(\mathrm{PR}_{\mathrm{CC}+\mathrm{SR}}\right.$, Figs. 5a,b) are obviously different from the diurnal cycles of precipitation rates for the all MCSs sample $\left(\mathrm{PR}_{\mathrm{all}}\right)$. In spring, relatively large precipitation rates are found between late afternoon and midnight over the NGP. Over the SGP, there are large diurnal variations of MCS precipitation, and particularly large precipitation rates are found from local noon to afternoon between $32^{\circ}$ and $34^{\circ} \mathrm{N}$, while heavy precipitation occurs almost the whole day between $34^{\circ}$ and $38^{\circ} \mathrm{N}$. In summer (Fig. 5b), large precipitation rates are found in the afternoon from $32^{\circ}$ to $34^{\circ} \mathrm{N}$, between midnight to early morning from $34^{\circ}$ to $38^{\circ} \mathrm{N}$, and from the late afternoon to midnight/early morning from $36^{\circ}$ to $48^{\circ} \mathrm{N}$.

The Hovmöller diagrams are also exhibited with longitude as the distance dimension, since this is the principal direction of precipitation system motion over North America. Eastward propagations of all MCS samples and their associated precipitation rates during the day can be seen in Figs. $3 \mathrm{c}$ and $3 \mathrm{~d}$ and Figs. $4 \mathrm{c}$ and $4 \mathrm{~d}$ over the Great Plains for both spring and summer. During spring, there are high occurrences of MCS distributions and associated precipitation rates from around local midnight to early morning with some evidence of initiation in the late afternoon to the east of $100^{\circ} \mathrm{W}$ (Figs. $3 \mathrm{c}$ and $4 \mathrm{c}$ ). Notice that the heavy precipitation rates $\left(\mathrm{PR}_{\mathrm{CC}+\mathrm{SR}}\right)$ can occur to the east of $100^{\circ} \mathrm{W}$ from local noon to midnight (Fig. 5c). During summer (Figs. 3d and 4d), it is obvious that MCSs $\left(\mathrm{PR}_{\mathrm{all}}\right)$ initiate during late afternoon close to the Rocky Mountain Front Range $\left(\sim 103^{\circ} \mathrm{W}\right)$, where the terrain has the sharpest gradient (Carbone et al. 2002). There are two different characteristics to the west and 
(a) Spring $\mathbf{P R}_{\mathrm{CC}+\mathrm{SR}}$

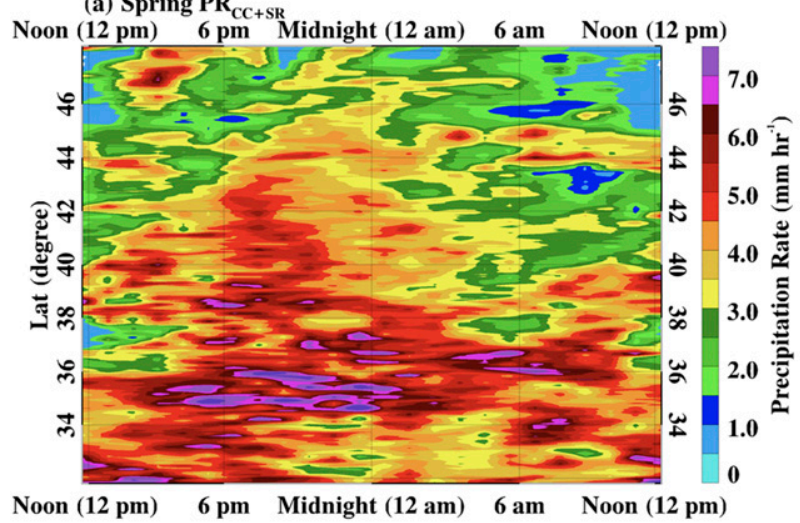

Local Time

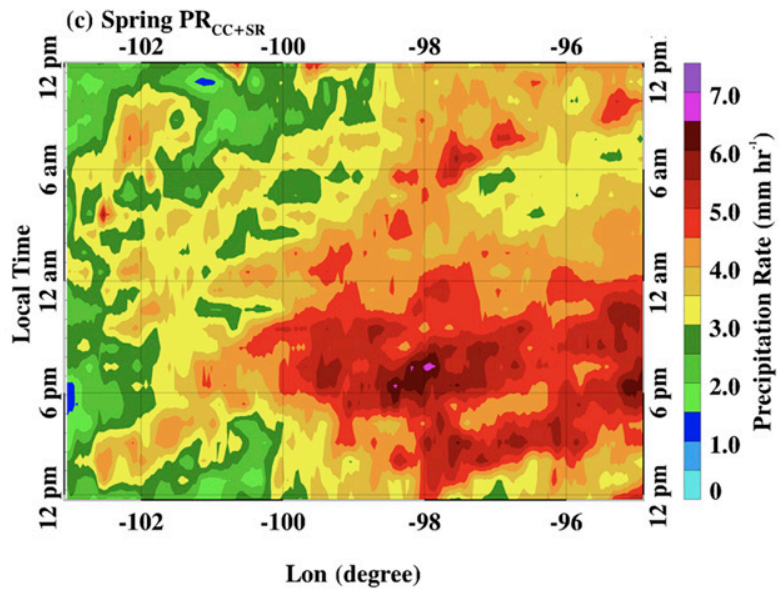

(b) Summer $\mathbf{P R}_{\mathrm{CC}+}$

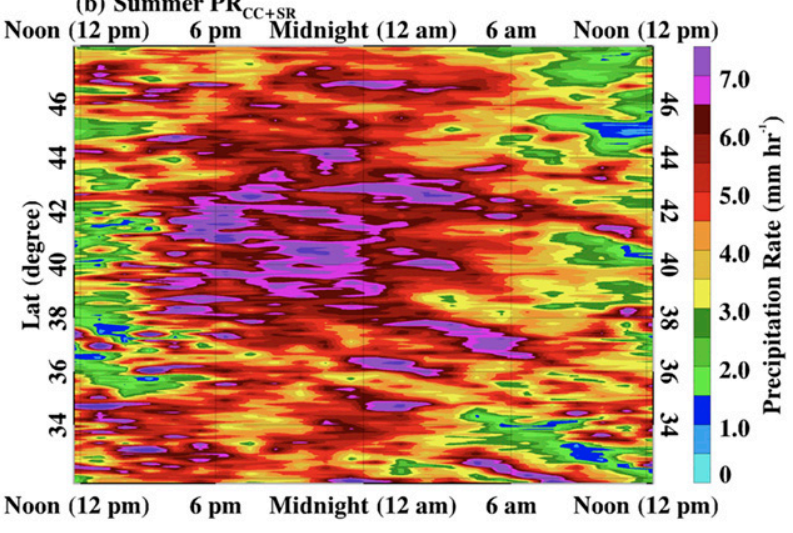

Local Time

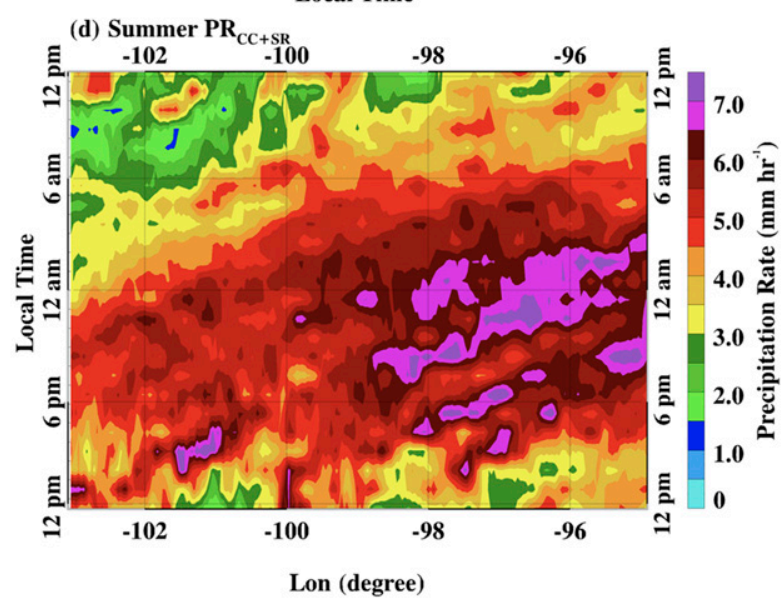

FIG. 5. As in Fig. 4, but for the precipitation rates in the $\mathrm{CC}$ and $\mathrm{SR}$ regions of $\mathrm{MCSs}\left(\mathrm{PR}_{\mathrm{CC}+\mathrm{SR}}\right)$.

east of $100^{\circ} \mathrm{W}$. Most of the MCSs and their associated precipitation occur from late afternoon $(\sim 1800 \mathrm{LT})$ to midnight $(\sim 0000 \mathrm{LT})$ to the west of $100^{\circ} \mathrm{W}$, whereas to the east of $100^{\circ} \mathrm{W}$, they peak from midnight to early morning with a much higher occurrence and heavier precipitation rate than those to the west of $100^{\circ} \mathrm{W}$. Comparing the Hovmöller diagrams of Figs. $3 \mathrm{c}$ and $3 \mathrm{~d}$ with Figs. $5 \mathrm{c}$ and $5 \mathrm{~d}$, it is found that, in general, the timings of heavy precipitation for $\mathrm{PR}_{\mathrm{all}}$ are earlier than those of $\mathrm{PR}_{\mathrm{CC}+\mathrm{SR}}$.

The spatial distributions of precipitation rate in the SR regions of MCSs $\left(\mathrm{PR}_{\mathrm{SR}}\right)$ are very consistent with those of $\mathrm{PR}_{\mathrm{CC}+\mathrm{SR}}$ in both spring and summer (figures are not shown). The correlation between $\mathrm{PR}_{\mathrm{CC}+\mathrm{SR}}$ and $\mathrm{PR}_{\mathrm{SR}}$ is $\sim 0.8$. The mean values of $\mathrm{PR}_{\mathrm{SR}}$ during spring $\left(2.34 \mathrm{~mm} \mathrm{~h}^{-1}\right)$ and summer $\left(2.43 \mathrm{~mm} \mathrm{~h}^{-1}\right)$ are quite close to each other. However, there are large spatial differences as illustrated in Figs. $6 \mathrm{a}$ and $6 \mathrm{~b}$. In spring, the maximum of $\mathrm{PR}_{\mathrm{SR}}$ occurs in northern Texas. Large spatial variations in $\mathrm{PR}_{\mathrm{SR}}$ are shown between the SGP and the NGP, where more large $\mathrm{PR}_{\mathrm{SR}}$ values occur over the SGP than over the NGP. In summer, the mean difference of $\mathrm{PR}_{\mathrm{SR}}$ between the SGP and the NGP is smaller $\left(0.07 \mathrm{~mm} \mathrm{~h}^{-1}\right)$ than that in spring $\left(0.24 \mathrm{~mm} \mathrm{~h}^{-1}\right)$ (Table 2). As summarized in Table 2, the $\mathrm{PR}_{\mathrm{SR}}$ values in summer are larger than those in spring, and the $\mathrm{PR}_{\mathrm{SR}}$ values over the SGP are slightly greater than their NGP counterparts.

Figure 7 shows the diurnal cycles of $\mathrm{PR}_{\mathrm{SR}}$ as a function of latitude or longitude during spring and summer. The frequency distributions of MCS precipitation in the SR regions (figures are also not shown) are almost the same as those for all MCS samples shown in Figs. 3a-d. In spring, we did not find very distinct diurnal cycles, but it is seen that the $\mathrm{PR}_{\mathrm{SR}}$ values are larger over the south than over the north. In summer, between $38^{\circ}$ and $48^{\circ} \mathrm{N}$, the diurnal cycles are more distinct, with large precipitation from the late afternoon to midnight/early morning, while between $32^{\circ}$ and $36^{\circ} \mathrm{N}$, large precipitation values are found at both noon and midnight.

The eastward propagation of MCSs during the day for both spring and summer can still be noticed in the SR regions (Figs. 7c,d), even though they are not as obvious 
(a) Spring $\mathbf{P R}_{\mathrm{SR}}$

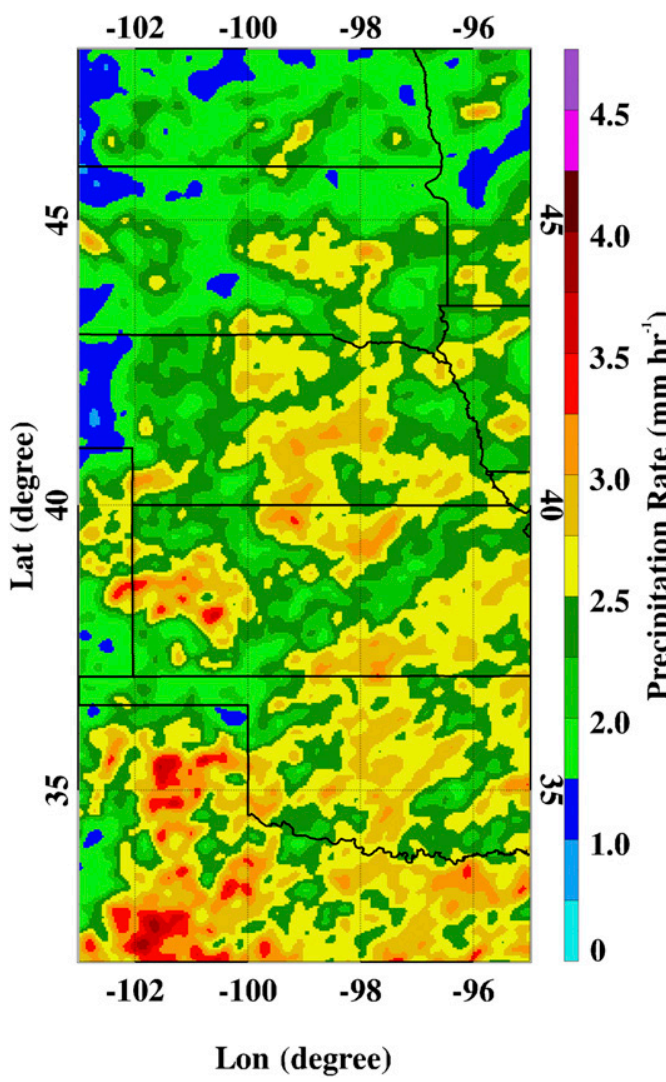

(b) Summer $\mathbf{P R}_{\mathrm{SR}}$

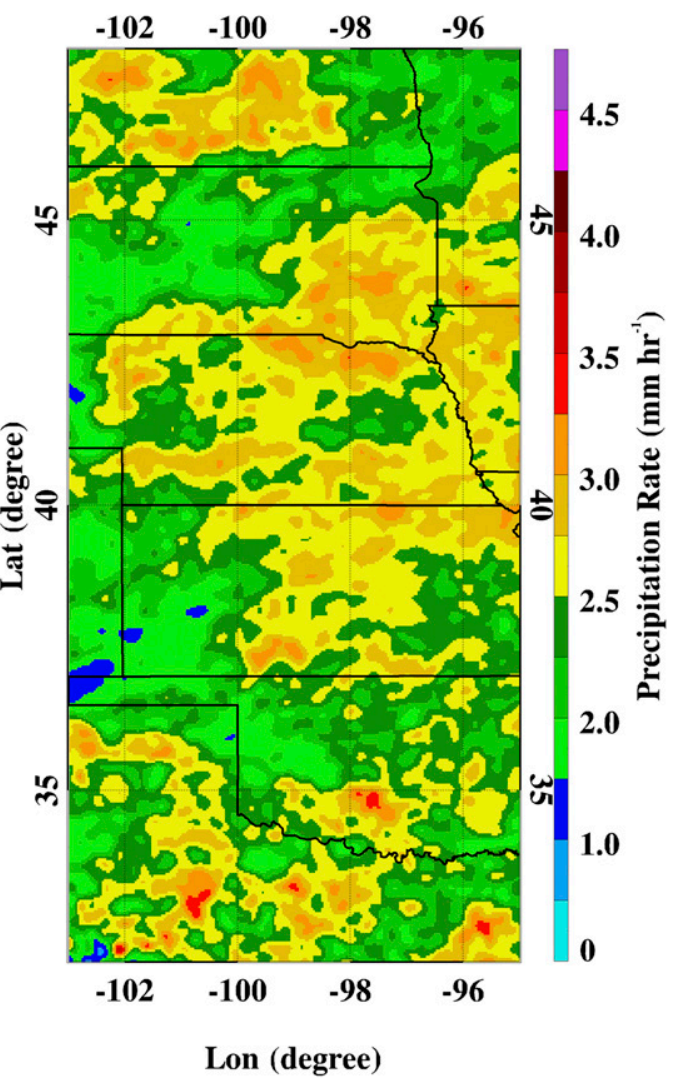

FIG. 6. Spatial distributions of the precipitation rates in the SR regions of MCSs $\left(\mathrm{PR}_{\mathrm{SR}}\right)$ during (a) spring and (b) summer.

as those shown in Figs. $4 c$ and $4 d$ or Figs. $5 c$ and $5 d$. During spring, $\mathrm{PR}_{\mathrm{SR}}$ values are large in the morning (0600-1200 LT) and afternoon (1200-1800 LT) to the west of $100^{\circ} \mathrm{W}$ and between $96^{\circ}$ and $98^{\circ} \mathrm{W}$. Over the regions between $98^{\circ}$ and $100^{\circ} \mathrm{W}, \mathrm{PR}_{\mathrm{SR}}$ values are large from noon to late night (1200-0000 LT). During summer, to the west of $100^{\circ} \mathrm{W}, \mathrm{PR}_{\mathrm{SR}}$ values are obviously much higher during afternoon than other time periods, in the afternoon. To the east of $100^{\circ} \mathrm{W}$, however, diurnal variations of $\mathrm{PR}_{\mathrm{SR}}$ are significantly different to those to the west of $100^{\circ} \mathrm{W}$ with large $\mathrm{PR}_{\mathrm{SR}}$ values during late afternoon and early morning. Even though the maximum of $\mathrm{PR}_{\mathrm{SR}}$ occurs around midnight, the SR precipitation could occur at any time of the day and varies with different locations and seasons with a less district diurnal cycle compared to $\mathrm{PR}_{\text {all }}$ and $\mathrm{PR}_{\mathrm{CC}+\mathrm{SR}}$.

\section{MCS ice cloud properties}

To investigate the characteristics of ice cloud properties in MCSs, we have generated a 3-yr database of MCS ice cloud properties using ground-based NEXRAD radar reflectivity over the Great Plains.

TABLE 2. The means and standard deviations of precipitation, IWC, and IWP of MCS SR regions at NGP and SGP in spring and summer. The values in IWC columns before and after the slash represent the mean or median values of IWCs calculated starting from 5 or $6 \mathrm{~km}$.

\begin{tabular}{llccc}
\hline \hline & NGP spring & NGP summer & SGP spring & SGP summer \\
\hline $\operatorname{PR}_{\mathrm{SR}}\left(\mathrm{mm} \mathrm{h}^{-1}\right)$ & $2.14 \pm 0.42$ & $2.48 \pm 0.33$ & $2.38 \pm 0.35$ & $2.55 \pm 0.37$ \\
$\mathrm{IWP}_{\mathrm{SR}}\left(\mathrm{kg} \mathrm{m}^{-2}\right)$ & $1.23 \pm 0.25$ & $1.89 \pm 0.34$ & $1.69 \pm 0.30$ & $2.12 \pm 0.29$ \\
$\mathrm{IWC}_{\mathrm{SR}}\left(\mathrm{g} \mathrm{m}^{-3}\right)$ & $0.29 \pm 0.31 /$ & $0.40 \pm 0.34 /$ & $0.37 \pm 0.33 /$ & $0.48 \pm 0.35 /$ \\
& $0.24 \pm 0.28$ & $0.34 \pm 0.30$ & $0.31 \pm 0.30$ & $0.38 \pm 0.31$ \\
\hline
\end{tabular}



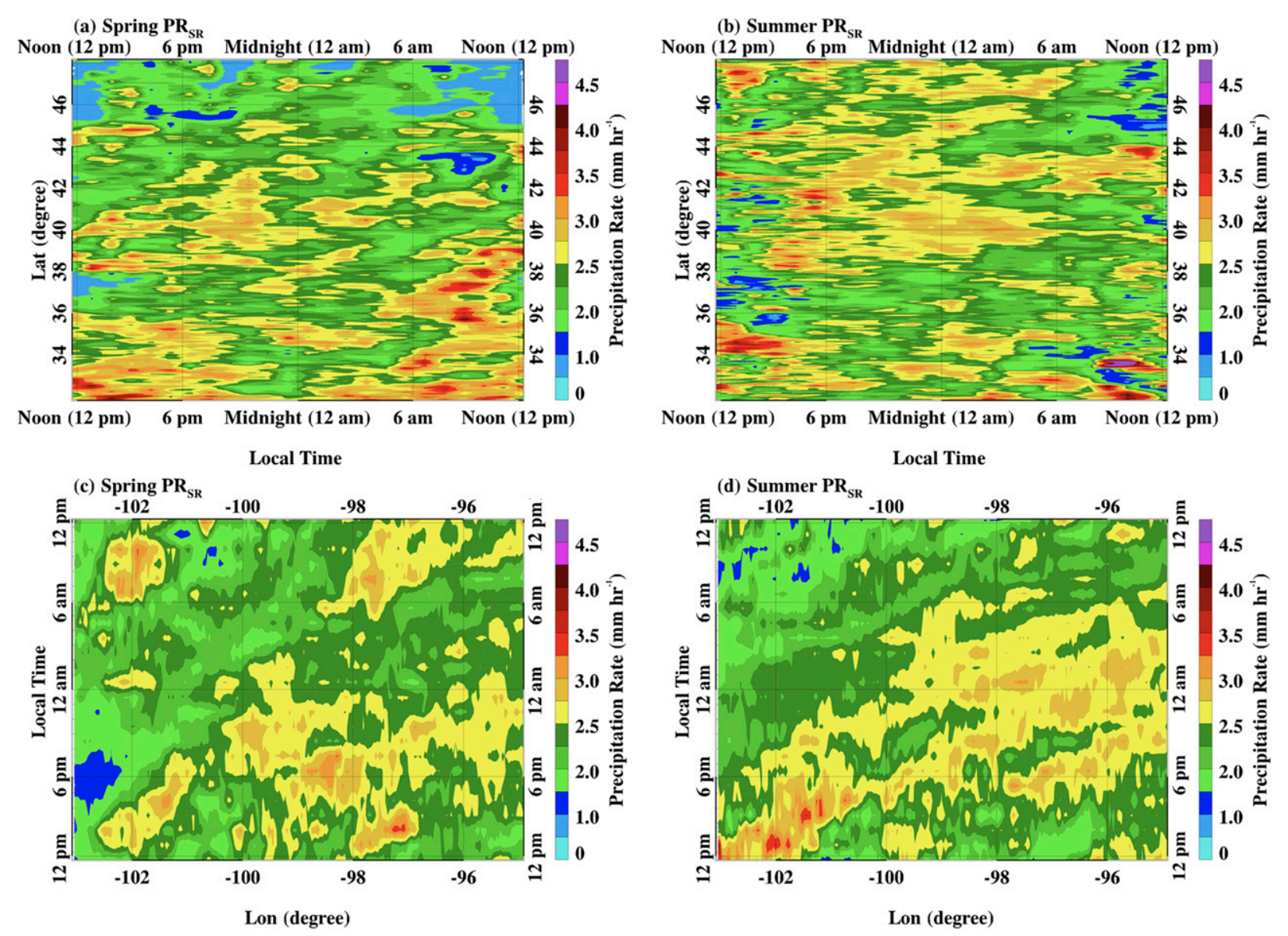

FIG. 7. Diurnal cycles of $\mathrm{PR}_{\mathrm{SR}}$ as a function of latitude and longitude during spring and summer.

The climatology of vertical distributions of IWCs above $5 \mathrm{~km}$ in the SR regions of MCSs is shown in Fig. 8, where IWC values generally decrease with height but with distinguishable differences for different seasons and regions. The mean IWC values $\left(\sim 0.1 \mathrm{~g} \mathrm{~m}^{-3}\right)$ are nearly the same for four datasets at an altitude of $12 \mathrm{~km}$, but at an altitude of $5 \mathrm{~km}$, they range from $\sim 0.4 \mathrm{~g} \mathrm{~m}^{-3}$ for spring over the NGP to $\sim 0.8 \mathrm{~g} \mathrm{~m}^{-3}$ for summer over the SGP. During spring, the mean values of IWC are 0.29 and $0.37 \mathrm{~g} \mathrm{~m}^{-3}$ at the NGP and SGP, but they are much larger during summer $\left(\mathrm{NGP}=0.40 \mathrm{~g} \mathrm{~m}^{-3}\right.$; SGP $=$ $0.48 \mathrm{~g} \mathrm{~m}^{-3}$ ). The overall mean value for the entire layer for four datasets is $0.39 \mathrm{~g} \mathrm{~m}^{-3}$.

IWP is the integration of IWC over an ice-dominate cloud layer. Consistent with IWC results, mean IWP values are larger in summer and over the SGP than those in spring and over the NGP (Fig. 9). A large difference exists between the spatial distributions in different seasons (spring and summer) and locations (SGP and NGP). The mean values are 1.23 and $1.69 \mathrm{~kg} \mathrm{~m}^{-2}$, respectively, for the NGP and the SGP in spring. In summer, both the SGP and the NGP have larger mean IWP values than those in spring. On average, the IWP in summer $\left(2.00 \mathrm{~kg} \mathrm{~m}^{-2}\right)$ is $37 \%$ more than that in spring $\left(1.46 \mathrm{~kg} \mathrm{~m}^{-2}\right)$. The IWC and IWP results are consistent with the precipitation patterns in the SR regions of MCSs, in which summer and SGP have larger $P_{S R}$ than spring and NGP.

Figure 10 shows the diurnal cycles of $\mathrm{IWP}_{\mathrm{SR}}$ as a function of latitude or longitude during spring and summer. It is again obvious that larger IWPs occur at the SGP than at the NGP during spring (Fig. 10a). Figure 10a also clearly reveals different IWP distributions over the Great Plains, for instance, large $\mathrm{IWP}_{\mathrm{SR}}$ values exist between $32^{\circ}$ and $34^{\circ} \mathrm{N}$ for nearly entire day, a southward propagation of $\mathrm{IWP}_{\mathrm{SR}}$ during the night from $34^{\circ}$ to $40^{\circ} \mathrm{N}$, and a northward propagation of IWP $\mathrm{SR}_{\mathrm{SR}}$ during the night from $42^{\circ}$ to $48^{\circ} \mathrm{N}$. Overall, the diurnal cycles of IWP $_{\mathrm{SR}}$ are latitude dependent during spring. In summer, large IWP $P_{S R}$ values occur almost everywhere and nearly the entire day (Fig. 10b).

Eastward propagation of $\mathrm{IWP}_{\mathrm{SR}}$ during the day can still be seen in the Great Plains for both spring and 


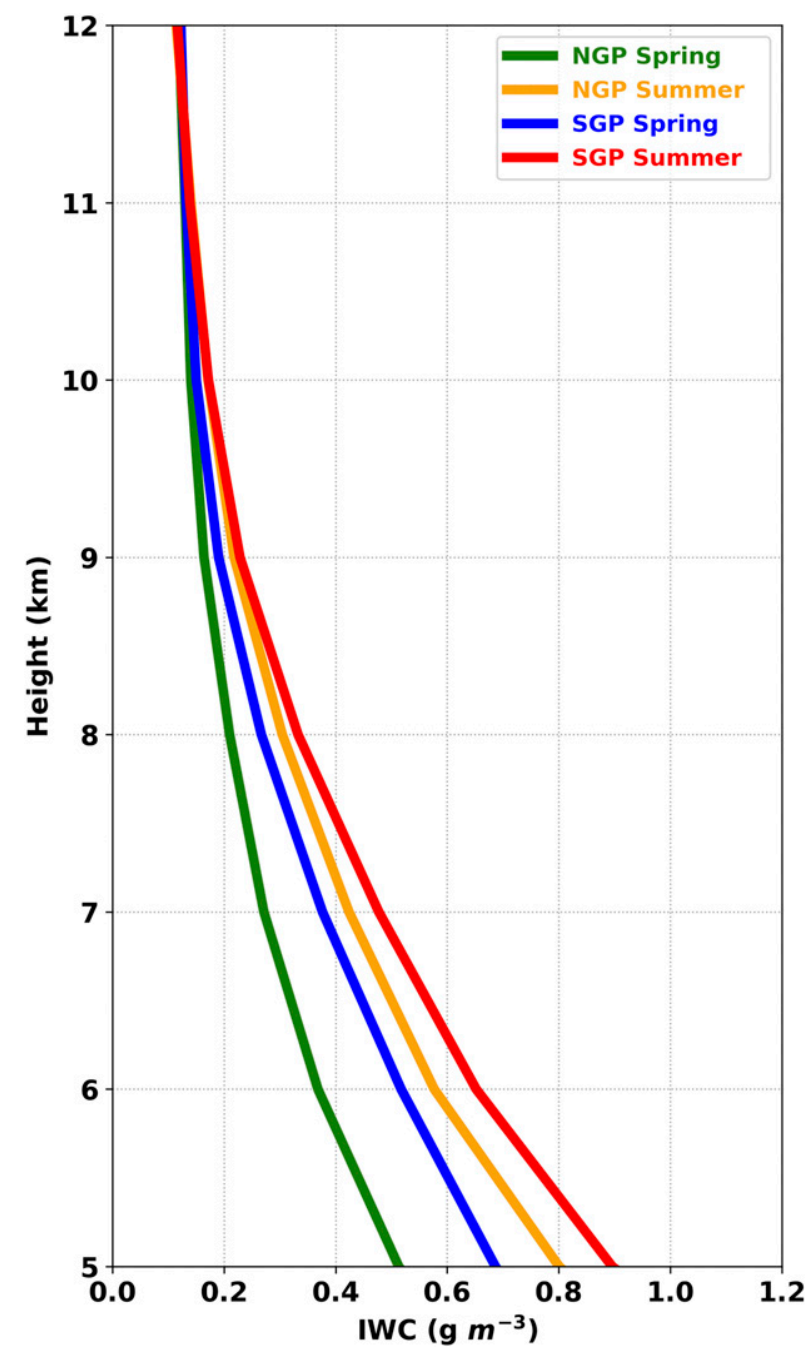

FIG. 8. Vertical profiles of retrieved IWCs in the SR regions of MCSs for two seasons (spring and summer) at the SGP and NGP. Lines show the mean values.

summer (Figs. 10c,d). During spring, IWP $_{\mathrm{SR}}$ values peak from afternoon to midnight between $95^{\circ}$ and $100^{\circ} \mathrm{W}$, while less distinct diurnal cycles identified over the west of $100^{\circ} \mathrm{W}$. In summer, eastward propagation of large $\mathrm{IWP}_{\mathrm{SR}}$ values from late afternoon to early morning can be seen between $98^{\circ}$ and $103^{\circ} \mathrm{W}$, as well as over the east of $96^{\circ} \mathrm{W}$.

\section{MCS ice cloud and precipitation relationships}

In sections 3 and 4, discussions are made for precipitation and ice properties of MCSs separately using spatial distributions and Hovmöller diagrams. This section aims at linking the MCS's ice cloud properties and precipitation. Figure 11 shows the diurnal variations of $\mathrm{PR}_{\mathrm{all}}, \mathrm{PR}_{\mathrm{CC}+\mathrm{SR}}, \mathrm{PR}_{\mathrm{SR}}$, and $\mathrm{IWP}_{\mathrm{SR}}$ over the
SGP and NGP during spring and summer. To better quantify these diurnal variations, a Fourier transform was applied to the diurnal cycles of MCS properties shown in Fig. 11. The first harmonic of the signal with a 24-h period was used (Wallace 1975). The amplitude and phase of the first harmonic of the diurnal cycles represent the strength of the diurnal cycle and the peak timing, respectively, while the percent variance explained by the first harmonic denotes how well a diurnal cycle can be represented by a sine wave (Gustafson et al. 2014). The phase (peak timing), amplitude, and percent variance explained for the first harmonic of MCS precipitation and IWP at the NGP and the SGP during spring and summer are listed in Table 3 . The peaks of $\mathrm{PR}_{\mathrm{all}}$ occur at midnight (2300-0100 LT), while the peaks of $\mathrm{PR}_{\mathrm{CC}+\mathrm{SR}}$ are $\sim 2 \mathrm{~h}$ earlier (210-2300 LT) than the peaks of $\mathrm{PR}_{\text {all }}$. This finding is partially consistent with the results of Dai et al. (2007), where they also found that the nocturnal peak precipitation is primarily driven by MCSs occurrences rather than by precipitation intensity. The 2-h shift in $\mathrm{PR}_{\text {all }}$ and $\mathrm{PR}_{\mathrm{CC}+\mathrm{SR}}$ indicates that even though the occurrence of MCSs is high around the midnight, there is indeed heavy precipitation (large $\mathrm{PR}_{\mathrm{CC}+\mathrm{SR}}$ values) around late night (2100-2300 LT). We applied a similar composite analysis to that used by Masunaga (2012). We set a reference time 0 when $\mathrm{PR}_{\mathrm{all}}$ peaks, and then generate a composite $\mathrm{PR}_{\mathrm{CC}+\mathrm{SR}}$ along the newly defined time axis. Our results showed that the peak timing of $\mathrm{PR}_{\mathrm{CC}+\mathrm{SR}}$ is at $-2 \mathrm{~h}$, which confirms that the peaks of $\mathrm{PR}_{\mathrm{CC}+\mathrm{SR}}$ are $\sim 2 \mathrm{~h}$ earlier than the peaks of $\mathrm{PR}_{\text {all }}$ (not shown). The amplitudes of precipitation and IWP are larger in summer than those in spring, suggesting that the diurnal cycle of MCS precipitation is stronger in summer than that in spring.

Comparing the percent variances explained for the first harmonic of precipitation and IWP of MCSs, it is noticed that the values are the smallest for the SGP during spring in Table 3, which indicates the diurnal cycles of precipitation and IWP at the SGP in spring are the least significant and the fitted sine waves using Fourier transform represent the diurnal cycles worst compared to the other regions and seasons. However, it is noticed that except for the values at the SGP during spring, the peak timing in precipitation shows a $0.5-1$-h delay in $\mathrm{PR}_{\mathrm{SR}}$ compared with IWP $_{\text {SR. Similarly, we also applied the composite }}$ analysis by Masunaga (2012) for $\mathrm{PR}_{\mathrm{SR}}$ and $\mathrm{IWP}_{\mathrm{SR}}$ with a reference time 0 when $P_{S R}$ peaks and then generated a composite of IWP $_{\mathrm{SR}}$ along the newly defined time axis. We found that the peak timing of IWP $_{\mathrm{SR}}$ occurs at $-1 \mathrm{~h}$, indicating the averaged peak 
(a) Spring IWP $\mathbf{S R}_{\mathrm{SR}}$

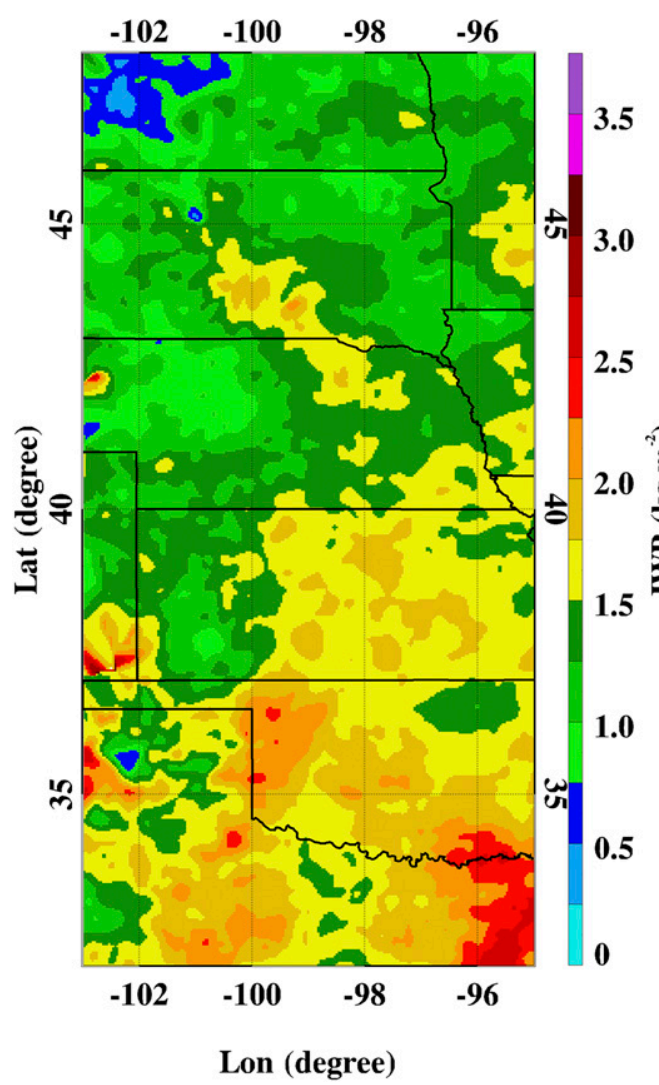

(b) Summer IWP

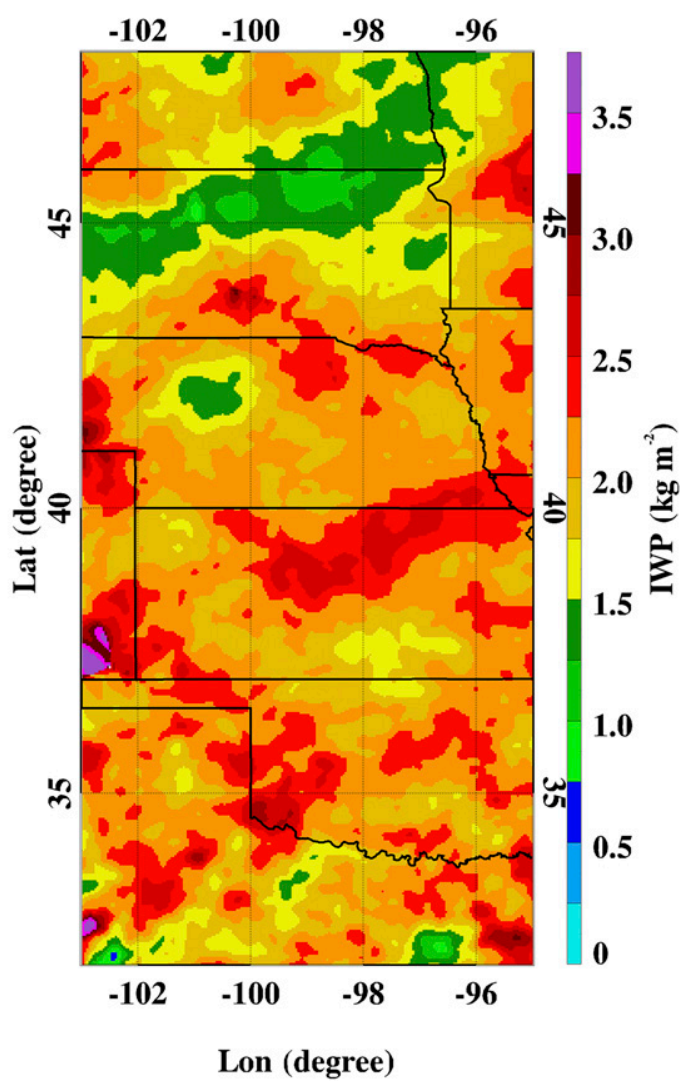

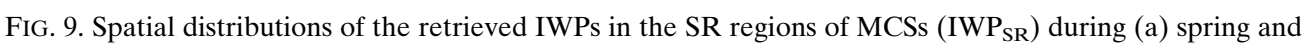

(b) summer.

timing of $\mathrm{IWP}_{\mathrm{SR}}$ is $\sim 1 \mathrm{~h}$ earlier than the peak timing of $\mathrm{PR}_{\mathrm{SR}}$.

In addition to comparing the diurnal cycles of IWP and precipitation of MCSs, their variations with MCSs evolution are also investigated. The composite evolutions of $\mathrm{PR}_{\mathrm{CC}}, \mathrm{PR}_{\mathrm{SR}}$, and $\mathrm{IWP}_{\mathrm{SR}}$ are shown in Fig. 12. For the composite evolution plot, Fig. 12, the four-dimensional IWPs (tracks, latitude, longitude, and time), are first averaged into two dimensions (tracks, time), and then the IWPs were averaged at the normalized time (in the composite, the MCSs lifetime are normalized from 0 to 1 ). Finally, IWPs were averaged along the tracks dimension. The $x$ axis represents the normalized MCS time, where 0 denotes convective initiation and 1 denotes dissipation. It is found that the peak timing of $\mathrm{PR}_{\mathrm{CC}}$ is earlier than the peak timing of IWP $_{\mathrm{SR}}$. Even though the variation of $\mathrm{PR}_{\mathrm{SR}}$ is not large, the peak timing of $\mathrm{PR}_{\mathrm{SR}}$ is later than that of $\mathrm{IWP}_{\mathrm{SR}}$. The shifts of peak timing in $\mathrm{PR}_{\mathrm{CC}}$, $\mathrm{PR}_{\mathrm{SR}}$, and $\mathrm{IWP}_{\mathrm{SR}}$ from both Figs. 11 and 12 can be summarized as following processes in the MCSs: 1) MCS CC regions contribute heavy precipitation first; then 2) the ice particles in the $\mathrm{CC}$ regions are detrained to the SR regions with depositional grow; and finally 3) the large ice particles travel/survive long distances, fall into dry layers, and eventually melt to raindrops and form the stratiform precipitation. Note that the results from both Figs. 11 and 12 are based on a 3-yr composite, and further investigations are needed for each tracked MCS, which is not the focus of our statistical-based study.

The relationships between $\mathrm{IWP}_{\mathrm{SR}}$ and $\mathrm{PR}_{\mathrm{SR}}$ are also investigated at different stages of MCSs, which are the genesis, mature, and decay stages. Scatterplots of IWP $_{\mathrm{SR}}$ against $\mathrm{PR}_{\mathrm{SR}}$ at three different stages of MCSs are illustrated in Fig. 13, and the $P_{S R}$ values are averaged in each IWP bin $\left(0.1 \mathrm{~kg} \mathrm{~m}^{-2}\right)$. To generate Fig. 13, we first averaged the IWP and precipitation spatially (latitude/longitude) at each time, reducing the data dimension to (track, time), and then further binned the precipitation by IWP bins. It is seen that the mature stage of MCSs tends to have higher $\mathrm{PR}_{\mathrm{SR}}$ than the genesis and mature stages of MCSs. Linear relationships are fitted between 

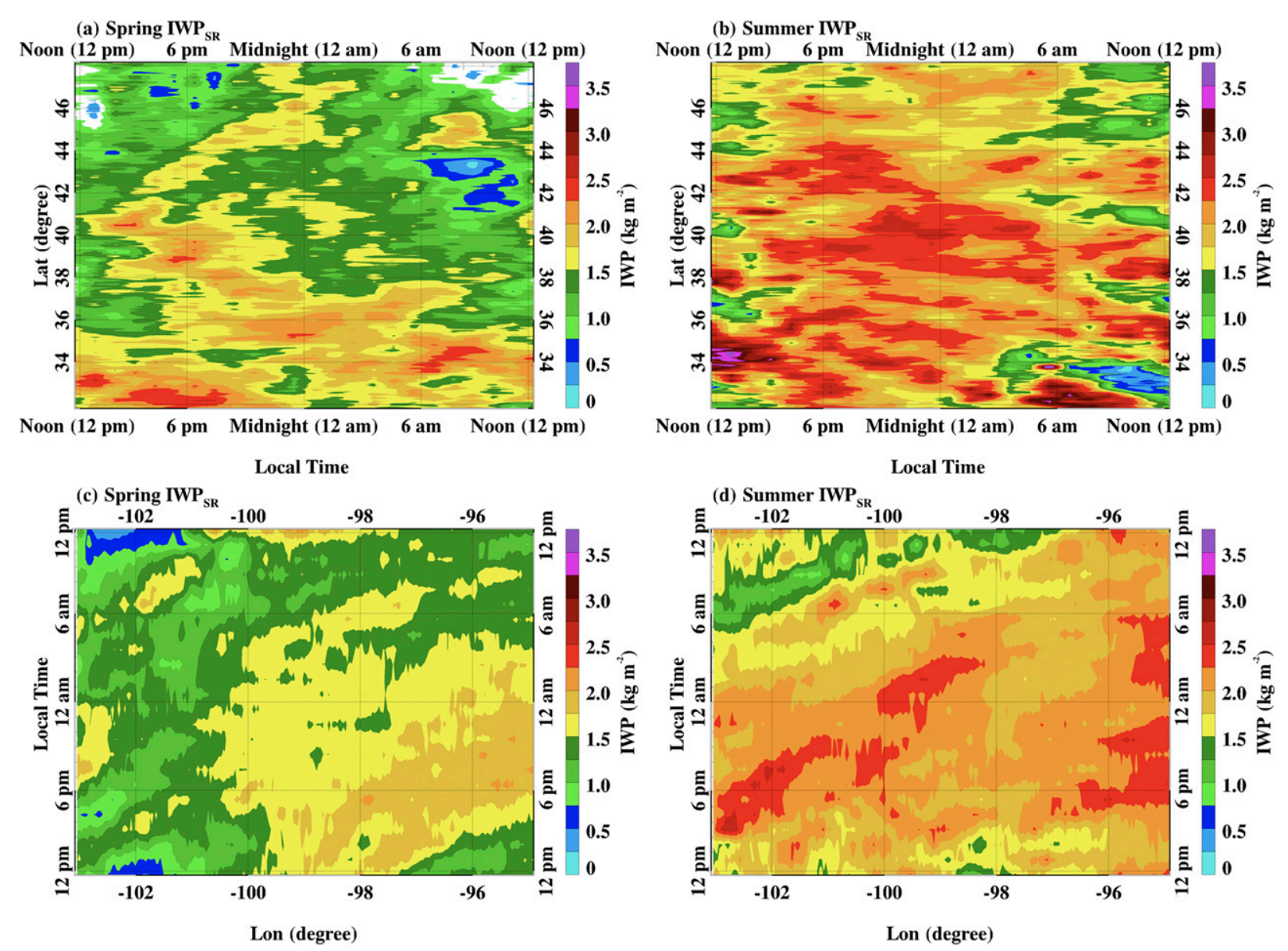

FIG. 10. Diurnal cycles of IWP $\mathrm{SR}_{\mathrm{SR}}$ as a function of latitude and longitude during spring and summer.

natural logarithm of $\mathrm{IWP}_{\mathrm{SR}}\left[\ln \left(\mathrm{IWP}_{\mathrm{SR}}\right)\right]$ and $\mathrm{PR}_{\mathrm{SR}}$ at each stage of MCSs, which are 1) genesis: $\mathrm{PR}_{\mathrm{SR}}=$ $\left.0.79 \times \ln \left(\mathrm{IWP}_{\mathrm{SR}}\right)+1.87 ; 2\right)$ mature: $\mathrm{PR}_{\mathrm{SR}}=0.33 \times$ $\ln \left(\mathrm{IWP}_{\mathrm{SR}}\right)+2.43$; and 3$)$ decay: $\mathrm{PR}_{\mathrm{SR}}=0.72 \times$ $\ln \left(\mathrm{IWP}_{\mathrm{SR}}\right)+1.90$. The slopes/correlations of the relationships at the genesis and decay stages are larger, while the slope/correlation at the mature stage is the smallest. The small correlation at the mature stage is consistent with the results presented in Fig. 12. At an earlier stage of MCSs (normalized time between 0.1 and 0.3 ), both $\mathrm{IWP}_{\mathrm{SR}}$ and $\mathrm{PR}_{\mathrm{SR}}$ increase with MCSs genesis. At a later stage of MCSs (normalized time between 0.5 and 0.9 ), both IWP $_{\mathrm{SR}}$ and $\mathrm{PR}_{\mathrm{SR}}$ decrease with MCS decay. However, in the middle/intensifying stage of MCSs (normalized time between 0.3 and 0.5 ), $\mathrm{IWP}_{\mathrm{SR}}$ decreases but $\mathrm{PR}_{\mathrm{SR}}$ increases, which results in a smaller correlation between IWP $_{\mathrm{SR}}$ and $\mathrm{PR}_{\mathrm{SR}}$ than other stages. Even though our derived relationships cannot directly be used in the satellite retrieval algorithm, our results indicate that different IWP $\mathrm{PR}_{\mathrm{SR}}$ and $\mathrm{PR}_{\mathrm{SR}}$ relationships should be used in the surface rain rate estimations, especially for those retrieval algorithms to retrieve IWP first and then use retrieved IWP to estimate surface rain rate with the prederived empirical relationship. In the future, some retrieved cloud variables (e.g., cloud optical depth and/or ice particle size) could be used to separate the MCS stages in the satellite retrieval combining different empirical relationships to estimate the surface rain rate.

The IWP-precipitation relations and the transition from ice cloud to precipitation are also investigated with considering the low-level humidity. Scatterplots of IWP $_{\mathrm{SR}}$ against $\mathrm{PR}_{\mathrm{SR}}$ are shown in Fig. 14. The relative humidity $(\mathrm{RH})$ data, from vertical levels from 925 to $700 \mathrm{hPa}$, are averaged in $\mathrm{PR}_{\mathrm{SR}}$ and IWP $_{\mathrm{SR}}$ bins, with bin widths of $0.2 \mathrm{~mm} \mathrm{~h}^{-1}$ and $0.2 \mathrm{~kg} \mathrm{~m}^{-2}$, respectively. As demonstrated in Fig. 14, RHs are higher during spring than during summer in the SR regions of MCSs. The typical range of $\mathrm{RH}$ values is from $50 \%$ to $90 \%$, indicating that the ice particles can be melted and eventually fall down to 

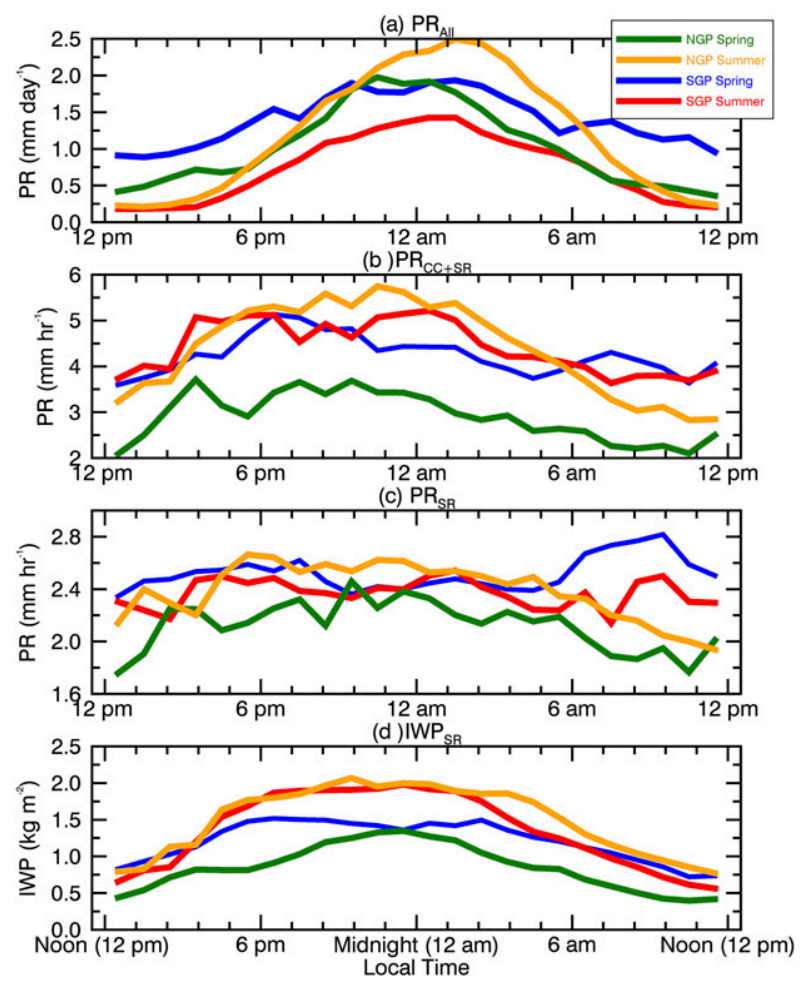

FIG. 11. Diurnal cycles of (a) $\mathrm{PR}_{\mathrm{all}}$, (b) $\mathrm{PR}_{\mathrm{CC}+\mathrm{SR}}$, (c) $\mathrm{PR}_{\mathrm{SR}}$, and (d) IWP $_{\mathrm{SR}}$ over the SGP and NGP during spring and summer.

the ground when the $\mathrm{RH}$ values exceed $50 \%$. More importantly, with given the same amount of ice (IWP), more precipitation can reach the ground under more humid conditions. When the ice particles are melted into raindrops and have fallen down to the lower levels with the increase of temperature, the raindrops have less chance to be evaporated if the subcloud layer is very humid. Thus, more precipitation can reach the ground (Kuligowski et al. 2013). We also noted that the figures for spring and summer are different, which is due to higher subcloud $\mathrm{RH}$ values during spring than during summer, but the dependences of IWP-precipitation relations (and the ice to precipitation transition process) on $\mathrm{RH}$ are found in both seasons and both the northern and southern Great Plains.

\section{Summary}

In this study, the MCSs are tracked using highresolution radar and satellite observations first over the U.S. Great Plains during the warm season (AprilAugust) from 2010 to 2012. The spatiotemporal variability of MCSs precipitation is characterized using the radar-based Stage IV product. To better understand the spatiotemporal distributions and ice clouds to the precipitation transition process in the MCSs, this study provides high-resolution, long-term, warmseason (April-August) ice cloud microphysical properties in the SR regions of MCSs over the Great Plains. Based on a 3-yr database of MCS precipitation and ice cloud properties, the main findings are summarized below.

The spatial distribution of $\mathrm{PR}_{\text {all }}$ exhibits a close resemblance to the MCS occurrence. A gradual northward migration of MCSs from the SGP in spring to the NGP in summer is found, so that the $\mathrm{PR}_{\mathrm{all}}$ is larger over the SGP $\left(1.39 \mathrm{~mm} \mathrm{day}^{-1}\right)$ than over the NGP $\left(1.03 \mathrm{~mm} \mathrm{day}^{-1}\right)$ during spring, while the $\mathrm{PR}_{\text {all }}$ is larger over the NGP $\left(1.21 \mathrm{~mm} \mathrm{day}^{-1}\right)$ than over the SGP $\left(0.73 \mathrm{~mm} \mathrm{day}^{-1}\right)$ during summer. The spatial distributions of $\mathrm{PR}_{\mathrm{CC}+\mathrm{SR}}$, however, are different from their $\mathrm{PR}_{\text {all }}$ counterparts. In both spring and summer, the $\mathrm{PR}_{\mathrm{CC}+\mathrm{SR}}$ is larger over the SGP than over the NGP. On average, the precipitation in summer $\left(4.18 \mathrm{~mm} \mathrm{~h}^{-1}\right)$ is $16 \%$ more than that in spring $\left(3.49 \mathrm{~mm} \mathrm{~h}^{-1}\right)$.

The nocturnal peak precipitation is primarily driven by MCS occurrence rather than by MCS precipitation intensity. The diurnal cycles of $\mathrm{PR}_{\mathrm{SR}}$ are not as significant as those of $\mathrm{PR}_{\text {all }}$. The mean values of $\mathrm{PR}_{\mathrm{SR}}$ during spring $\left(2.34 \mathrm{~mm} \mathrm{~h}^{-1}\right)$ and summer $\left(2.43 \mathrm{~mm} \mathrm{~h}^{-1}\right)$ are quite close to each other, but there are large spatial differences. Overall, $\mathrm{PR}_{\mathrm{SR}}$ values are larger in summer and over the SGP than those in the spring and over the NGP.

Based on the 3-yr dataset of IWC above $5 \mathrm{~km}$ in the MCS stratiform regions, we found that IWC values generally decrease with height, but with distinguishable differences for different seasons and regions. The mean IWC values $\left(\sim 0.1 \mathrm{~g} \mathrm{~m}^{-3}\right)$ are nearly the same for four datasets at an altitude of $12 \mathrm{~km}$, but at an altitude

TABLE 3. The phase (peak timing), amplitude, and percent variance explained for the first harmonic of precipitation and IWP of MCSs at NGP and SGP in spring and summer.

\begin{tabular}{lcccc}
\hline \hline & NGP spring & NGP summer & SGP spring & SGP summer \\
\hline PR $_{\text {all }}$ & $23.19 / 0.73 / 46.75$ & $0.42 / 1.14 / 49.30$ & $23.78 / 0.46 / 45.64$ & $0.16 / 0.62 / 49.33$ \\
RR $_{C C+S R}$ & $21.66 / 0.87 / 46.79$ & $22.63 / 2.00 / 48.47$ & $21.08 / 1.02 / 46.19$ & $22.62 / 1.77 / 48.04$ \\
PR $_{\text {SR }}$ & $22.94 / 0.47 / 47.68$ & $23.56 / 0.77 / 46.33$ & $21.85 / 0.32 / 40.95$ & $23.25 / 0.78 / 47.77$ \\
IWP $_{\text {SR }}$ & $22.38 / 0.42 / 48.07$ & $22.61 / 0.62 / 47.17$ & $22.01 / 0.34 / 43.09$ & $22.04 / 0.69 / 48.16$ \\
\hline
\end{tabular}



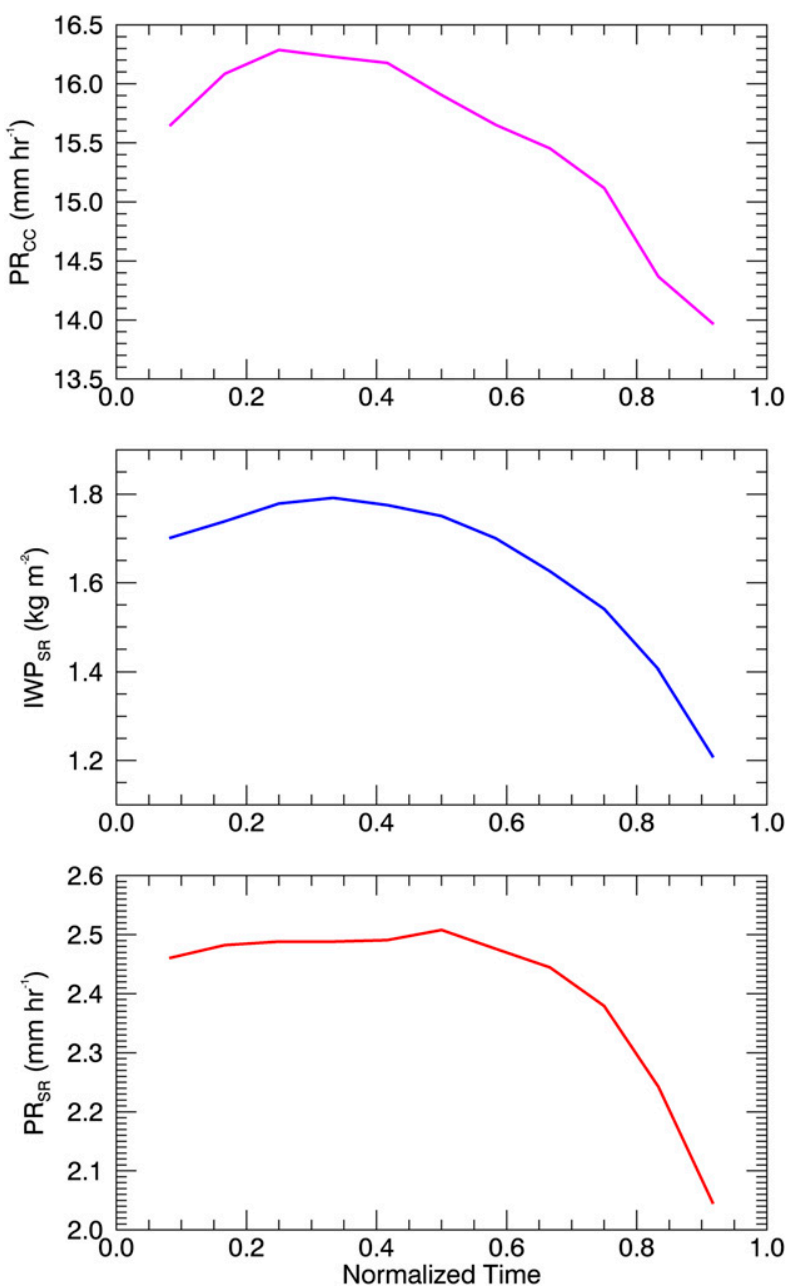

FIG. 12. Composite evolutions of (a) PRs in the CC regions of MCSs $\left(\mathrm{PR}_{\mathrm{CC}}\right)$, (b) IWP $\mathrm{IWR}_{\mathrm{SR}}$, and (c) $\mathrm{PR}_{\mathrm{SR}}$. The $x$ axis shows normalized MCSs time, where 0 denotes convective initiation and 1 denotes dissipation.

of $5 \mathrm{~km}$, they range from $\sim 0.4 \mathrm{~g} \mathrm{~m}^{-3}$ for spring over the NGP to $\sim 0.8 \mathrm{~g} \mathrm{~m}^{-3}$ for summer over the SGP. During spring, the mean values of IWC are 0.29 and $0.37 \mathrm{~g} \mathrm{~m}^{-3}$ at the NGP and SGP, while they are 0.40 and $0.48 \mathrm{~g} \mathrm{~m}^{-3}$ during summer. The overall mean value for the entire layer for four datasets is $0.39 \mathrm{~g} \mathrm{~m}^{-3}$. The corresponding mean values of $\mathrm{IWP}_{\mathrm{SR}}$ are 1.23 $\left(1.89 \mathrm{~kg} \mathrm{~m}^{-2}\right)$ and $1.69 \mathrm{~kg} \mathrm{~m}^{-2}\left(2.12 \mathrm{~kg} \mathrm{~m}^{-2}\right)$ over the NGP and SGP in spring (summer), respectively. The IWC and IWP results are consistent with the precipitation patterns in the SR regions of MCSs, in which summer and the SGP have larger $\mathrm{PR}_{\mathrm{SR}}$ than during spring and over the NGP.

Through comparing the peak timings of MCS precipitation and IWP from the diurnal cycles and their composite evolutions, we found that when using the peak timing of $\mathrm{IWP}_{\mathrm{SR}}$ as a reference, the heaviest

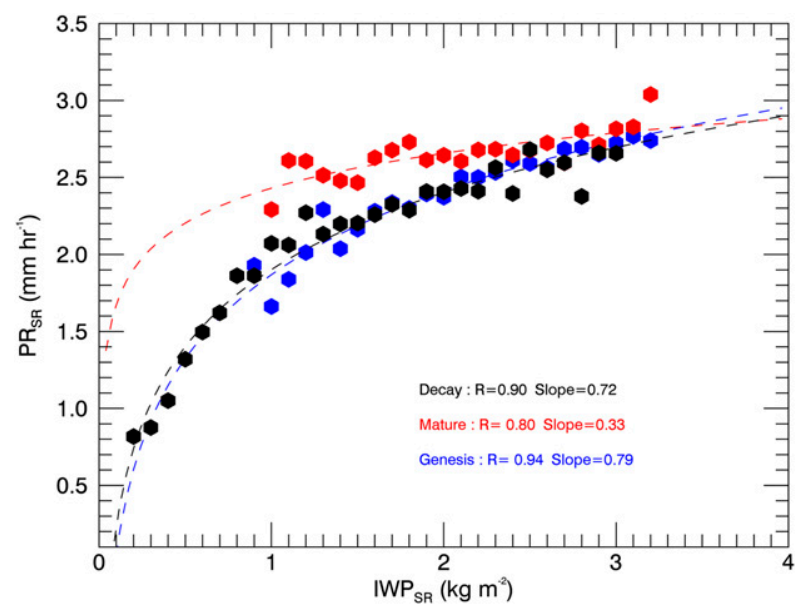

FIG. 13. Scatterplot of $\mathrm{IWP}_{\mathrm{SR}}$ against $\mathrm{PR}_{\mathrm{SR}}$ at three different stages of MCSs (genesis, blue; mature, red; decay, black). The $\mathrm{PR}_{\mathrm{SR}}$ values are averaged in each IWP bin. The bin width of IWP is $0.1 \mathrm{~kg} \mathrm{~m}^{-2}$. The colorful lines represent the linear fit between $\mathrm{PR}_{\mathrm{SR}}$ and the natural logarithm of $\mathrm{IWP}_{\mathrm{SR}}$ for three stages of MCSs.

precipitation in the MCS convective core is earlier, whereas the strongest SR precipitation occurs $\sim 0.5-1 \mathrm{~h}$ later. The shifts of peak timing in $\mathrm{PR}_{\mathrm{CC}}, \mathrm{PR}_{\mathrm{SR}}$, and IWP $_{\mathrm{SR}}$ from both Figs. 11 and 12 can be summarized as the following processes in the MCSs: 1) MCS CC regions contribute heavy precipitation first; then 2) the ice particles in the CC regions are detrained to the SR regions with depositional growth; and finally 3) the large ice particles travel/survive long distances, fall into dry layers, and eventually melt to raindrops and form the stratiform precipitation.

The relationships between $\mathrm{IWP}_{\mathrm{SR}}$ and $\mathrm{PR}_{\mathrm{SR}}$ are also investigated at MCS genesis, mature, and decay stages. The slopes/correlations of the relationships at the genesis and decay stages are similar to each other and larger, while the slope/correlation at the mature stage is the smallest. Our results indicate that different $\mathrm{IWP}_{\mathrm{SR}}$ and $\mathrm{PR}_{\mathrm{SR}}$ relationships should be used in the surface rain rate estimations, especially in those retrieval algorithms that retrieve IWP first and then use retrieved IWP to estimate surface rain rate with the prederived empirical relationship. In this study, we found that the $\mathrm{IWP}_{\mathrm{SR}}$ and $\mathrm{PR}_{\mathrm{SR}}$ relationships also depend on the low-level humidity and the transition processes from ice to precipitation depending on how humid it is in the subcloud layer. With the same amount of ice (IWP), more precipitation tends to fall down to the surface due to less evaporation of raindrops in a more humid layer.

Through an analysis of 3-yr of MCS ice cloud properties, we found different spatiotemporal distributions 
(a) Spring NGP

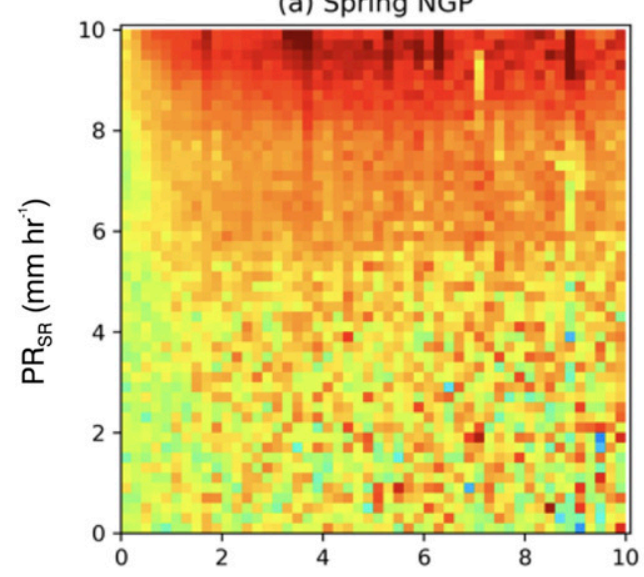

(c) Spring SGP

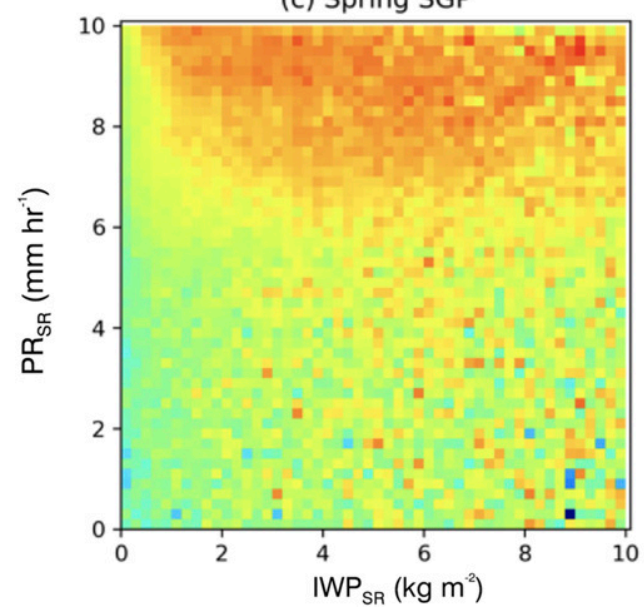

(b) Summer NGP

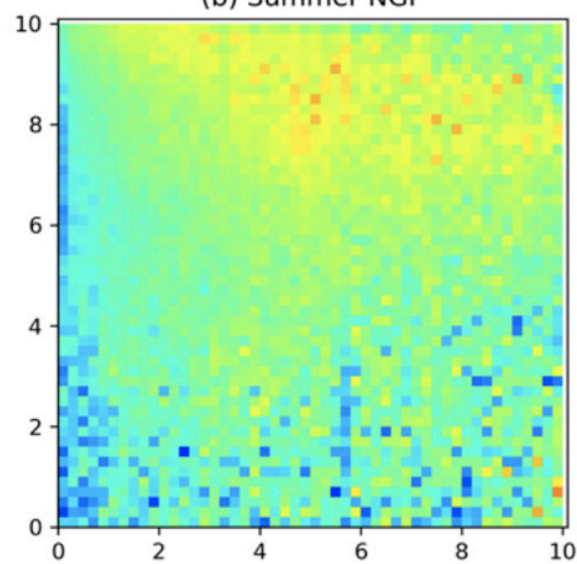

(d) Summer SGP

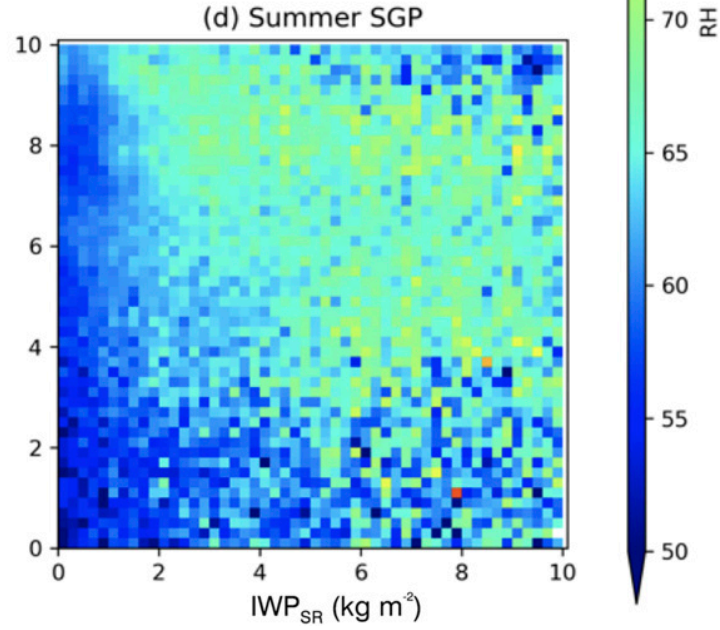

FIG. 14. Scatterplots of $I_{W P}$ SR against $P_{R_{S R}}$ for two seasons (spring and summer) at the SGP and NGP. The relative humidity $(\mathrm{RH})$ data are averaged in $\mathrm{PR}_{\mathrm{SR}}$ and $I W P_{\mathrm{SR}}$ bins. The bin widths of $\mathrm{PR}_{\mathrm{SR}}$ and $I W \mathrm{P}_{\mathrm{SR}}$ are $0.2 \mathrm{~mm} \mathrm{~h}^{-1}$ and $0.2 \mathrm{~kg} \mathrm{~m}^{-2}$.

of retrieved IWPs during spring and summer over the northern and southern Great Plains. What about model simulations? Are they similar to the observations? Also, from observations and retrievals, we found that the peak timings of $\mathrm{PR}_{\mathrm{CC}}$ and $\mathrm{PR}_{\mathrm{SR}}$ are earlier and later than the peak of $I_{W P}$, respectively. Can the models simulate the observed patterns? Those questions could be answered in further work. Combining this dataset with model simulations would have great potential to better understand the microphysical processes of MCSs and their transition processes from ice cloud particles to precipitation.

Acknowledgments. This research was primarily supported by the Climate Model Development and Validation (CMDV) program funded by the Office of Biological and Environmental Research in the U.S. Department of Energy Office of Science under
Grant DE-SC0017015 at the University of Arizona. Drs. Dong and $\mathrm{Xi}$ are also supported by NASA CERES project under Grant 80NSSC19K0172 at The University of Arizona. The GridRad radar dataset is obtained from the Research Data Archive of the National Center for Atmospheric Research (NCAR) (https://doi.org/10.5065/D6NK3CR7), the Stage IV data are obtained from the NCAR Earth Observing Laboratory (https://data.eol.ucar.edu/dataset/21.093). The NARR dataset is obtained from NOAA Earth System Research Laboratory Physical Science Division (https:// www.esrl.noaa.gov/psd/data/narr/). The MCS database is obtained from the U.S. Department of Energy Atmospheric Radiation Measurement program (https://doi.org/10.5439/ 1571643). The results of this study can be obtained from Xiquan Dong (xdong@email.arizona.edu). This work was performed under the auspices of the U.S. Department of Energy by Lawrence Livermore National Laboratory under Contract DE-AC52-07NA27344, Lawrence Livermore 
National Security, LLC. Information release LLNLJRNL-798906.

\section{REFERENCES}

AghaKouchak, A., A. Behrangi, S. Sorooshian, K. Hsu, and E. Amitai, 2011: Evaluation of satellite-retrieved extreme precipitation rates across the central United States. J. Geophys. Res., 116, D02115, https://doi.org/10.1029/2010JD014741.

Ashley, W. S., T. L. Mote, P. G. Dixon, S. L. Trotter, E. J. Powell, J. D. Durkee, and A. J. Grundstein, 2003: Distribution of mesoscale convective complex rainfall in the United States. Mon. Wea. Rev., 131, 3003-3017, https://doi.org/10.1175/15200493(2003)131<3003:DOMCCR > 2.0.CO;2.

Bentley, M. L., and J. A. Sparks, 2003: A $15 \mathrm{yr}$ climatology of derecho-producing mesoscale convective systems over the central and eastern United States. Climate Res., 24, 129-139, https://doi.org/10.3354/cr024129.

Bowman, K. P., and C. R. Homeyer, 2017: GridRad - ThreeDimensional Gridded NEXRAD WSR-88D Radar Data, V3.1. NCAR Computational and Information Systems Laboratory, accessed 1 November 2018, https://doi.org/ 10.5065/D6NK3CR7.

Bringi, V. N., and V. Chandrasekar, 2001: Polarimetric Doppler Weather Radar: Principles and Applications. Cambridge University Press, 648 pp.

Carbone, R. E., and A. R. Bohne, 1975: Cellular snow generation-A Doppler radar study. J. Atmos. Sci., 32, 1384-1394, https://doi.org/ 10.1175/1520-0469(1975)032<1384:CSGDRS > 2.0.CO;2.

_ J. D. Tuttle, D. A. Ahijevych, and S. B. Trier, 2002: Inferences of predictability associated with warm season precipitation episodes. J. Atmos. Sci., 59, 2033-2056, https://doi.org/10.1175/ 1520-0469(2002)059<2033:IOPAWW >2.0.CO;2.

Comstock, K. K., R. Wood, S. E. Yuter, and C. S. Bretherton, 2004: Reflectivity and rain rate in and below drizzling stratocumulus. Quart. J. Roy. Meteor. Soc., 130, 2891-2918, https:// doi.org/10.1256/qj.03.187.

Cui, W., X. Dong, B. Xi, J. Fan, J. Tian, J. Wang, and T. M. McHardy, 2019: Understanding ice cloud-precipitation properties of three modes of mesoscale convective systems during PECAN. J. Geophys. Res. Atmos., 124, 4121-4140, https://doi.org/ 10.1029/2019JD030330.

Dai, A., X. Lin, and K. L. Hsu, 2007: The frequency, intensity, and diurnal cycle of precipitation in surface and satellite observations over low- and mid-latitudes. Climate Dyn., 29, 727-744, https://doi.org/10.1007/s00382-007-0260-y.

Fan, J., and Coauthors, 2017: Cloud-resolving model intercomparison of an MC3E squall line case: Part I-Convective updrafts. J. Geophys. Res. Atmos., 122, 9351-9378, https:// doi.org/10.1002/2017JD026622.

Feng, Z., X. Dong, B. Xi, C. Schumacher, P. Minnis, and M. Khaiyer, 2011: Top-of-atmosphere radiation budget of convective core/stratiform rain and anvil clouds from deep convective systems. J. Geophys. Res., 116, D23202, https:// doi.org/10.1029/2011JD016451.

—, L. R. Leung, S. Hagos, R. A. Houze, C. D. Burleyson, and K. Balaguru, 2016: More frequent intense and long-lived storms dominate the springtime trend in central US rainfall. Nat. Commun., 7, 13429, https://doi.org/10.1038/ncomms13429.

__ , and Coauthors, 2018: Structure and evolution of mesoscale convective systems: Sensitivity to cloud microphysics in convection-permitting simulations over the United States.
J. Adv. Model. Earth Syst., 10, 1470-1494, https://doi.org/ 10.1029/2018MS001305.

, R. A. Houze, L. R. Leung, F. Song, J. C. Hardin, J. Wang, W. I. Gustafson, and C. R. Homeyer, 2019: Spatiotemporal characteristics and large-scale environments of mesoscale convective systems east of the Rocky Mountains. J. Climate, 32, 7303-7328, https://doi.org/10.1175/JCLI-D-19-0137.1.

Ferraro, F., N. Weng, C. Grody, and L. Zhao, 2000: Precipitation characteristics over land from the NOAA-15 AMSU sensor. Geophys. Res. Lett., 27, 2669-2672, https://doi.org/10.1029/ 2000 GL011665.

Fiolleau, T., and R. Roca, 2013: Composite life cycle of tropical mesoscale convective systems from geostationary and low Earth orbit satellite observations: Method and sampling considerations. Quart. J. Roy. Meteor. Soc., 139, 941-953, https:// doi.org/10.1002/qj.2174.

Fridlind, A. M., and Coauthors, 2017: Derivation of aerosol profiles for MC3E convection studies and use in simulations of the 20 May squall line case. Atmos. Chem. Phys., 17, 5947-5972, https://doi.org/10.5194/acp-17-5947-2017.

Giangrande, S. E., S. Collis, A. K. Theisen, and A. Tokay, 2014: Precipitation estimation from the ARM distributed radar network during the MC3E campaign. J. Appl. Meteor. Climatol., 53, 2130-2147, https://doi.org/10.1175/JAMC-D-13-0321.1.

Gustafson, W. I., P.-L. Ma, and B. Singh, 2014: Precipitation characteristics of CAM5 physics at mesoscale resolution during $\mathrm{MC} 3 \mathrm{E}$ and the impact of convective timescale choice. J. Adv. Model. Earth Syst., 6, 1271-1287, https://doi.org/ 10.1002/2014MS000334.

Han, B., and Coauthors, 2019: Cloud-resolving model intercomparison of an MC3E squall line case: Part II. Stratiform precipitation properties. J. Geophys. Res. Atmos., 124, 1090-1117, https://doi.org/10.1029/2018JD029596.

Han, J., and S. Hong, 2018: Precipitation forecast experiments using the Weather Research and Forecasting (WRF) Model at gray-zone resolutions. Wea. Forecasting, 33, 1605-1616, https://doi.org/10.1175/WAF-D-18-0026.1.

Hartmann, D. L., M. E. Ockert-Bell, and M. L. Michelsen, 1992: The effect of cloud type on Earth's energy balance: Global analysis. J. Climate, 5, 1281-1304, https://doi.org/10.1175/15200442(1992)005<1281:TEOCTO > 2.0.CO;2.

Herzegh, P. H., and P. V. Hobbs, 1980: The mesoscale and microscale structure and organization of clouds and precipitation in midlatitude cyclones. II: Warm-frontal clouds. J. Atmos. Sci., 37, 597-611, https://doi.org/10.1175/15200469(1980)037<0597:TMAMSA > 2.0.CO;2.

Heymsfield, A. J., 1977: Precipitation development in stratiform ice clouds: A microphysical and dynamical study. J. Atmos. Sci., 34, 367-381, https://doi.org/10.1175/1520-0469(1977) $034<0367$ :PDISIC $>2.0$.CO;2.

Houze, R. A., 2004: Mesoscale convective systems. Rev. Geophys., 42, RG4003, https://doi.org/10.1029/2004RG000150.

Janowiak, J. E., R. J. Joyce, and Y. Yarosh, 2001: A real-time global half-hourly pixel-resolution infrared dataset and its applications. Bull. Amer. Meteor. Soc., 82, 205-217, https://doi.org/ 10.1175/1520-0477(2001)082<0205:ARTGHH>2.3.CO;2.

Jiang, X., N.-C. Lau, and S. A. Klein, 2006: Role of eastward propagating convection systems in the diurnal cycle and seasonal mean of summertime rainfall over the U.S. Great Plains. Geophys. Res. Lett., 33, L19809, https://doi.org/ 10.1029/2006GL027022.

Khain, A., T. V. Prabha, N. Benmoshe, G. Pandithurai, and M. Ovchinnikov, 2013: The mechanism of first raindrops 
formation in deep convective clouds. J. Geophys. Res. Atmos., 118, 9123-9140, https://doi.org/10.1002/JGRD.50641.

Kubar, T. L., D. L. Hartmann, and R. Wood, 2009: Understanding the importance of microphysics and macrophysics for warm rain in marine low clouds. Part I: Satellite observations. J. Atmos. Sci., 66, 2953-2972, https://doi.org/10.1175/2009JAS3071.1.

Kuligowski, R. J., Y. Li, and Y. Zhang, 2013: Impact of TRMM data on a low-latency, high-resolution precipitation algorithm for flash-flood forecasting. J. Appl. Meteor. Climatol., 52, 1379-1393, https://doi.org/10.1175/JAMC-D-12-0107.1.

Lebsock, M., H. Morrison, and A. Gettelman, 2013: Microphysical implications of cloud-precipitation covariance derived from satellite remote sensing. J. Geophys. Res. Atmos., 118, 6521-6533, https://doi.org/10.1002/JGRD.50347.

Lin, Y., 2011: GCIP/EOP Surface: Precipitation NCEP/EMC 4KM Gridded Data (GRIB) Stage IV Data, version 1.0. UCAR/NCAR-Earth Observing Laboratory, accessed 1 November 2017, https://doi.org/10.5065/D6PG1QDD.

Lu, Y., K. Aydin, E. E. Clothiaux, and J. Verlinde, 2015: Retrieving cloud ice water content using millimeter- and centimeterwavelength radar polarimetric observables. J. Appl. Meteor. Climatol., 54, 596-604, https://doi.org/10.1175/JAMC-D-14-0169.1.

Masunaga, H., 2012: Short-term versus climatological relationship between precipitation and tropospheric humidity. J. Climate, 25, 7983-7990, https://doi.org/10.1175/JCLI-D-12-00037.1.

Mehran, A., and A. AghaKouchak, 2014: Capabilities of satellite precipitation datasets to estimate heavy precipitation rates at different temporal accumulations. Hydrol. Processes, 28, 2262-2270, https://doi.org/10.1002/hyp.9779.

Morrison, H., J. A. Milbrandt, G. H. Bryan, K. Ikeda, S. A. Tessendorf, and G. Thompson, 2015: Parameterization of cloud microphysics based on the prediction of bulk ice particle properties. Part II: Case study comparisons with observations and other schemes. J. Atmos. Sci., 72, 312-339, https://doi.org/10.1175/JAS-D-14-0066.1.

Nakazawa, T., 1988: Tropical super clusters within intraseasonal variations over the western Pacific. J. Meteor. Soc. Japan, 66, 823-839, https://doi.org/10.2151/jmsj1965.66.6_823.

Nesbitt, S. W., R. Cifelli, and S. A. Rutledge, 2006: Storm morphology and rainfall characteristics of TRMM precipitation features. Mon. Wea. Rev., 134, 2702-2721, https://doi.org/ 10.1175/MWR3200.1.

Prein, A. F., C. Liu, K. Ikeda, R. Bullock, R. M. Rasmussen, G. J. Holland, and M. Clark, 2017: Simulating North American mesoscale convective systems with a convection-permitting climate model. Climate Dyn., https://doi.org/10.1007/s00382-017-3993-2.

Smalley, M., T. L'Ecuyer, M. Lebsock, and J. Haynes, 2014: A comparison of precipitation occurrence from the NCEP stage IV QPE product and the CloudSat Cloud Profiling Radar. J. Hydrometeor., 15, 444-458, https://doi.org/10.1175/JHM-D-13-048.1.

Song, F., Z. Feng, L. R. Leung, R. A. Houze Jr., J. Wang, J. Hardin, and C. R. Homeyer, 2019: Contrasting spring and summer large-scale environments associated with mesoscale convective systems over the U.S. Great Plains. J. Climate, 32, 6749-6767, https://doi.org/10.1175/JCLI-D-18-0839.1.

Starzec, M., C. R. Homeyer, and G. L. Mullendore, 2017: Storm labeling in three dimensions (SL3D): A volumetric radar echo and dual-polarization updraft classification algorithm. Mon. Wea. Rev., 145, 1127-1145, https://doi.org/10.1175/MWR-D-16-0089.1.

Stephens, G. L., and Coauthors, 2002: The Cloudsat Mission and the A-Train: A new dimension of space-based observations of clouds and precipitation. Bull. Amer. Meteor. Soc., 83, 17711790, https://doi.org/10.1175/BAMS-83-12-1771.
_ - and Coauthors, 2012: An update on Earth's energy balance in light of the latest global observations. Nat. Geosci., 5, 691-696, https://doi.org/10.1038/ngeo1580.

Tian, J., X. Dong, B. Xi, J. Wang, C. Homeyer, G. McFarquhar, and J. Fan, 2016: Retrievals of ice cloud microphysical properties of deep convective systems using radar measurements. J. Geophys. Res. Atmos., 121, 10 820-10 839, https://doi.org/10.1002/2015JD024686.

, - —, P. Minnis, W. L. Smith Jr., S. Sun-Mack, M. Thiemann, and J. Wang, 2018: Comparisons of ice water path in deep convective systems among ground-based, GOES, and CERES-MODIS retrievals. J. Geophys. Res. Atmos., 123, 1708-1723, https://doi.org/10.1002/2017JD027498.

C. R. Williams, and P. Wu, 2019: Estimation of liquid water path below the melting layer in stratiform precipitation systems using radar measurements during MC3E. Atmos. Meas. Tech., 12, 3743-3759, https://doi.org/10.5194/amt-12-3743-2019.

Varble, A., and Coauthors, 2014: Evaluation of cloud-resolving and limited area model intercomparison simulations using TWP-ICE observations: 2. Precipitation microphysics. J. Geophys. Res. Atmos., 119, 13 919-13 945, https://doi.org/10.1002/2013JD021372.

Wallace, J. M., 1975: Diurnal variations in precipitation and thunderstorm frequency over the conterminous United States. Mon. Wea. Rev., 103, 406-419, https://doi.org/10.1175/15200493(1975)103<0406:DVIPAT>2.0.CO;2.

Wang, J., X. Dong, A. Kennedy, B. Haggenhoff, and B. Xi, 2019: A regime based evaluation of Southern and Northern Great Plains warm season precipitation events in WRF. Wea. Forecasting, 34, 805-831, https://doi.org/10.1175/WAF-D-19-0025.1.

Wang, S.-Y., T.-C. Chen, and J. Correia, 2011a: Climatology of summer midtropospheric perturbations in the U.S. northern plains. Part I: Influence on northwest flow severe weather outbreaks. Climate Dyn., 36, 793-810, https://doi.org/10.1007/ s00382-009-0696-3.

$\longrightarrow, \ldots$, and E. S. Takle, 2011b: Climatology of summer midtropospheric perturbations in the US northern plains. Part II: Large-scale effects of the Rocky Mountains on genesis. Climate Dyn., 36, 1221-1237, https://doi.org/10.1007/s00382-010-0765-7.

Weng, F., L. Zhao, R. Ferraro, G. Poe, X. Li, and N. Grody, 2003: Advanced microwave sounding unit cloud and precipitation algorithms. Radio Sci., 38, 8068-8079, https://doi.org/10.1029/ 2002RS002679.

Wood, R., 2012: Stratocumulus clouds. Mon. Wea. Rev., 140, 2373-2423, https://doi.org/10.1175/MWR-D-11-00121.1.

Wu, P., X. Dong, and B. Xi, 2015: Marine boundary layer drizzle properties and their impact on cloud property retrieval. Atmos. Meas. Tech., 8, 3555-3562, https://doi.org/10.5194/amt-8-3555-2015.

,,,--- Y. Liu, M. Thieman, and P. Minnis, 2017: Effects of environment forcing on marine boundary layer clouddrizzle processes. J. Geophys. Res. Atmos., 122, 4463-4478, https://doi.org/10.1002/2016JD026326.

_ B. Xi, X. Dong, and Z. Zhang, 2018: Evaluation of autoconversion and accretion enhancement factors in general circulation model warm-rain parameterizations using groundbased measurements over the Azores. Atmos. Chem. Phys., 18, 17 405-17 420, https://doi.org/10.5194/acp-18-17405-2018.

You, Y., and G. Liu, 2012: The relationship between surface rainrate and water paths and its implications to satellite rainrate retrieval. J. Geophys. Res., 117, D13207, https://doi.org/ 10.1029/2012JD017662.

Zhao, L. and F. Weng, 2002: Retrieval of ice cloud parameters using the Advanced Microwave Sounding Unit. J. Appl. Meteor., 41, 384-395, https://doi.org/10.1175/1520-0450(2002) $041<0384:$ ROICPU $>2.0$. CO;2. 